\title{
Could Late Cretaceous sauropod tooth morphotypes provide supporting evidence for faunal connections between North Africa and Southern Europe?
}

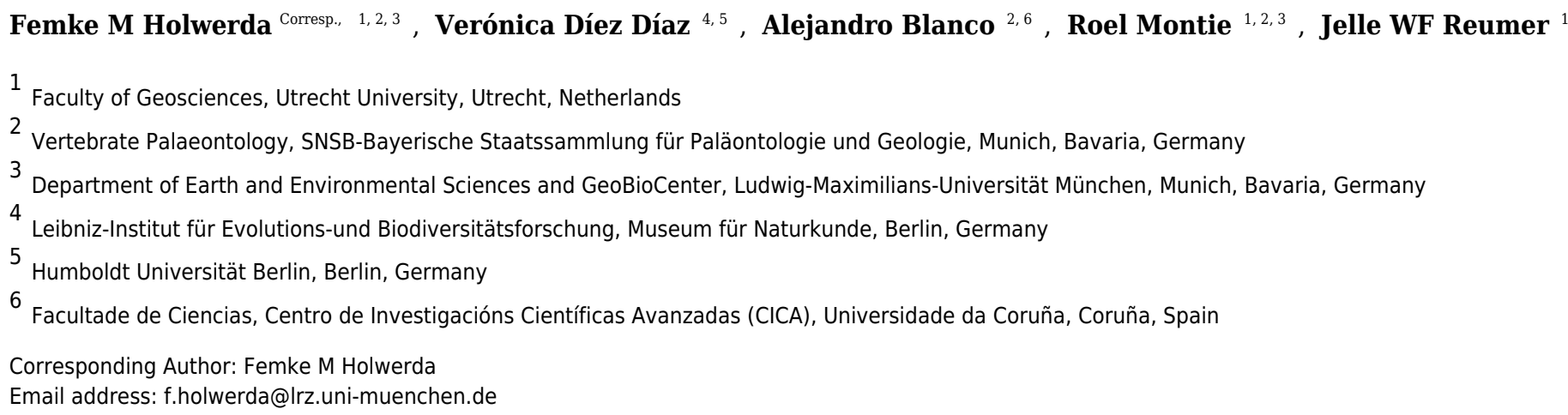

The Cretaceous Kem Kem beds of Morocco and equivalent beds in Algeria have produced a rich fossil assemblage, yielding, amongst others, isolated sauropod teeth, which can be used in species diversity studies. These Albian-Cenomanian ( 113 - 93.9 Ma) strata rarely yield sauropod body fossils, therefore, isolated teeth can help to elucidate the faunal assemblages from North Africa, and their relations with those of contemporaneous beds and geographically close assemblages. Eighteen isolated sauropod teeth from three localities (Erfoud and Taouz, Morocco, and Algeria) are studied here, to assess whether the teeth can be ascribed to a specific clade, and whether different tooth morphotypes can be found in the samples. Two general morphotypes are found, based on enamel wrinkling and general tooth morphology. Morphotype I, with mainly rugose enamel wrinkling, pronounced carinae, lemon-shaped to (sub)cylindrical cross-section and mesiodistal tapering towards an apical tip, shows affinities to titanosauriforms and titanosaurs. Morphotype II, characterized by more smooth enamel, cylindrical cross-section, rectangular teeth with no apical tapering and both labial and lingual wear facets, shows similarities to rebbachisaurids. Moreover, similarities are found between these northwest African tooth morphotypes, and tooth morphotypes from titanosaurs and rebbachisaurids from both contemporaneous finds from north and central Africa, as well as from the latest Cretaceous (Campanian-Maastrichtian, $83.6 \mathrm{Ma}-66.0 \mathrm{Ma}$ ) of the Ibero-Armorican Island. These results support previous hypotheses from earlier studies on faunal exchange and continental connections between North Africa and Southern Europe in the Cretaceous. 
1 Could Late Cretaceous sauropod tooth morphotypes provide supporting evidence for

2 faunal connections between North Africa and Southern Europe?

3

4 Femke M. Holwerda*1,2,3, Verónica Díez Díaz ${ }^{4,5}$, Alejandro Blanco ${ }^{2,6}$, Roel Montie ${ }^{1,2,3}$ and Jelle 5 W.F. Reumer ${ }^{1}$

6

$7 \quad{ }^{1}$ Faculty of Geosciences, Utrecht University, Princetonlaan 8a, 3584 CB Utrecht, The

8 Netherlands;

$9{ }^{2}$ Staatliche Naturwissenschaftliche Sammlungen Bayerns (SNSB), Bayerische; Staatssammlung

10 für Paläontologie und Geologie, Richard Wagnerstrasse 10, 80333 Munich, Germany;

$11{ }^{3}$ Department of Earth and Environmental Sciences and GeoBioCenter, Ludwig Maximilians

12 Universität, 80333 Munich, Germany;

$13{ }^{4}$ Museum für Naturkunde, Leibniz-Institut für Evolutions-und Biodiversitätsforschung,

14 Invalidenstraße 43, 10115 Berlin, Germany;

$15{ }^{5}$ Humboldt Universität, Berlin, Germany;

$16{ }^{6}$ Centro de Investigacións Científicas Avanzadas (CICA), Facultade de Ciencias, Universidade

17 da Coruña, 15071 A Coruña, Spain

18

19 *Corresponding author: f.m.holwerda@gmail.com

21 ABSTRACT

22 The Cretaceous Kem Kem beds of Morocco and equivalent beds in Algeria have produced a rich

23 fossil assemblage, yielding, amongst others, isolated sauropod teeth, which can be used in 
24 species diversity studies. These Albian-Cenomanian ( 113 - 93.9 Ma) strata rarely yield

25

sauropod body fossils, therefore, isolated teeth can help to elucidate the faunal assemblages from North Africa, and their relations with those of contemporaneous beds and geographically close assemblages. Eighteen isolated sauropod teeth from three localities (Erfoud and Taouz, Morocco, and Algeria) are studied here, to assess whether the teeth can be ascribed to a specific clade, and whether different tooth morphotypes can be found in the samples. Two general morphotypes are found, based on enamel wrinkling and general tooth morphology. Morphotype I, with mainly rugose enamel wrinkling, pronounced carinae, lemon-shaped to (sub)cylindrical cross-section and mesiodistal tapering towards an apical tip, shows affinities to titanosauriforms and titanosaurs. Morphotype II, characterized by more smooth enamel, cylindrical cross-section, rectangular teeth with no apical tapering and both labial and lingual wear facets, shows similarities to rebbachisaurids. Moreover, similarities are found between these northwest African tooth morphotypes, and tooth morphotypes from titanosaurs and rebbachisaurids from both contemporaneous finds from north and central Africa, as well as from the latest Cretaceous (Campanian-Maastrichtian, $83.6 \mathrm{Ma}-66.0 \mathrm{Ma}$ ) of the Ibero-Armorican Island. These results support previous hypotheses from earlier studies on faunal exchange and continental connections between North Africa and southern Europe in the Cretaceous.

\section{INTRODUCTION}

The early Late Cretaceous of northwestern Africa is well-known for its rich vertebrate fauna, many taxa having been described in particular from the Albian-Cenomanian $(\sim 113-93.9 \mathrm{Ma})$ Kem Kem beds of Morocco, and the Albian-Cenomanian equivalent continental intercalaire of Algeria. The Moroccan Kem Kem beds include aquatic fauna such as sharks, lungfish, 
47 coelacanths, bony fish, amphibians, turtles, crocodylomorphs, as well as terrestrial vertebrates

48 such as squamates, pterosaurs, sauropods, and an abundance of theropods (Lavocat, 1954;

49 Russell, 1996; Sereno et al., 1996; Wellnhofer \& Buffetaut, 1999; Cavin et al., 2010; Richter,

50 Mudroch \& Buckley, 2013; Läng et al., 2013; Mannion \& Barrett, 2013). Despite this large

51 diversity, most fossil material consists of isolated elements from theropods and chondrichthyans

52 (e.g. Spinosaurus, Carcharodontosaurus, Onchopristis, Läng et al., 2013; C. Underwood

53 pers.comm. 2018). Läng et al. (2013) attributed this to the deltaic palaeoenvironment being

54 unsuitable for the setting of stable terrestrial vegetation. Because of this, the herbivorous fauna

55 has not received much attention thus far, and sauropod material is rare (C. Underwood, pers. comm. 2018, but see McGowan \& Dyke, 2009). Studies of sauropod material from this region thus far found Rebbachisaurus garasbae, and other rebbachisaurids (Lavocat, 1954; de Lapparent \& Gorce, 1960; Russell, 1996; Mannion \& Barrett, 2013; Wilson \& Allain, 2015) as well as several titanosauriform remains, and also a possible titanosaurian (De Broin, Grenot \& Vernet, 1971; Kellner \& Mader, 1997; Mannion \& Barrett, 2013; Lamanna \& Hasegawa, 2014; Ibrahim et al., 2016). De Lapparent \& Gorce (1960) also mentioned brachiosaurid finds, however, these remains are now considered to be rebacchisaurid or titanosauriform (Mannion, 2009; Mannion \& Barrett, 2013).

Sauropod body fossils are restricted to mostly isolated elements, or, if associated, material is not as numerous as with theropod material (see e.g. Mahler, 2005; Novas, Dalla Vecchia \& Pais, 2005; Cau \& Maganuco, 2009). Sauropod teeth, however, are preserved in relative abundance.

67 One isolated sauropod tooth had already been reported on by Kellner \& Mader, 1997. Sauropod 68 teeth are commonly preserved in the fossil record due to their hardness, resilience against 69 weathering, and due to their high tooth replacement rates (see e.g. Calvo, 1994; Erickson, 1996; 
70 García \& Cerda, 2010). Studying isolated teeth has previously been applied to assessing

71 theropod species diversity in North Africa (Richter, Mudroch \& Buckley, 2013). Sauropod teeth

72 can be used for a similar purpose as well, as morphological classifications based on shape, size

73 and position of wear facets (Calvo, 1994; Salgado \& Calvo, 1997; Chure et al., 2010; Mocho et

74 al., 2016; Carballido et al., 2017), and enamel wrinkling patterns (Carballido \& Pol, 2010; Díez

75 Díaz, Suberbiola \& Sanz, 2012; Díez Díaz, Tortosa \& Le Loeuff, 2013; Holwerda, Pol \&

76 Rauhut, 2015) have classified tooth assemblages into morphotypes or even down to family or

77 genus level (e.g. Amygdalodon, Patagosaurus).

78 Mannion \& Barrett (2013) suggested that the Cretaceous North African titanosauriforms may not

79 be closely related to southern African forms, as the lineages were cut off from each other by the

80 trans-Saharan seaway. Moreover, close relations are suggested between Cretaceous North

81 African sauropods and Italian sauropods (Zarcone et al., 2010; Dal Sasso et al., 2016), and

82 Iberian sauropods (Sallam et al., 2018; Díez Díaz et al., 2018). More specifically, close relations

83 between Egyptian and European sauropods (Sallam et al., 2018) and between Tunisian and

84 European sauropods (Fanti et al., 2015) have been found. These studies proposed faunal

85 exchanges during the Late Cretaceous between northern Africa and southern Europe. Several

86 migratory routes have been suggested, such as the 'Apulian route' during the Early Cretaceous

87 (Dalla Vecchia, 2002; Canudo et al., 2009). Continental connections would have been made

88 possible by peri-Adriatic carbonate platforms in the Mediterranean, connecting North Africa

89 with Adria, throughout the Cretaceous, making migration possible between the northern African

90 and southern European islands and peninsulas (Zarcone et al., 2010). Indeed, these carbonate

91 platforms contain numerous tetrapod footprints, including those of sauropods (Zarcone et al.,

92 2010). The hypothesis of a faunal exchange during the Cretaceous is not new; Late Cretaceous 
93 abelisaurid theropods and titanosaurian sauropods from France are found to have Gondwanan

94 affinities, indicating migration from Gondwana to Europe, an event which could already have

95 taken place in the Early Cretaceous (Buffetaut, Mechin \& Mechin-Salessy, 1988; Buffetaut,

96 1989). Next to sauropods, Early Cretaceous abelisaurid and carcharodontosaurid theropods were

97 found with Gondwanan affinities, as well as other terrestrial fauna, such as amphibians, snakes,

98 and ziphodont crocodyliforms (Le Loeuff, 1991; Vullo et al., 2005; Vullo, Neraudeau \& Lenglet,

99 2007; Pereda-Suberbiola, 2009). Ösi, Apesteguía \& Kowalewski, (2010) found Santonian

100 theropods from the Mediterranean region to have both Gondwanan and North American

101 affinities. Dalla Vecchia \& Cau (2011) added a notosuchian from the Late Cretaceous of Italy,

102 and Rabi \& Sebök, (2015) a sebecosuchian to this faunal assemblage with Gondwanan affinities.

103 Reviewing undescribed North African Cretaceous sauropod material could add information on

104 both the biogeographical patterns of the Euro-Gondwanan area, as well as on sauropod species

105 diversity in northwestern Africa.

106 Here, we present a morphological and quantitative analysis of a sauropod tooth assemblage from

107 the Cenomanian of Morocco and Algeria. Teeth are categorized into two morphotypes, which are

108 then compared to contemporaneous Cretaceous sauropod tooth morphotypes, including sauropod

109 teeth from Africa and southern Europe.

\section{Institutional abbreviations:}

113 BSPG: Bayerische Staatssammlung für Paläontologie und Geologie, Munich, Germany

114 FAM: Fox-Amphoux-Métisson, France

115 MB.R.: Museum für Naturkunde, Berlin, Germany 
116 MCCM-HUE: Museo de las Ciencias de Castilla-la Mancha, Spain

117 MHN-AIX-PV: Natural History Museum Aix-en-Provence, France

118 MPCA-Pv: Museo Provincial “Carlos Ameghino”, colección de paleovertebrados, Río Negro,

119 Argentina

120 PIMUZ: Palaeontological Institute and Museum, University of Zürich, Switzerland

\section{GEOLOGICAL SETTING}

123 Fourteen of the teeth studied here are from the Kem Kem beds of Morocco, and four were

124 supposedly found in the Late Cretaceous Continental Intercalaire of Algeria. Four of the

125 Moroccan sample are labeled as originating from 'Taouz, Algeria,' and four are labeled 'Kem

126 Kem Morocco'. Taouz, Algeria, might actually mean Taouz, Morocco, which is the southern part

127 of the Kem Kem beds, and ten samples are labeled as originating from Erfoud, Morocco, which

128 is the more northern part of the Kem Kem beds (Figure 1). The Kem Kem area is located in the

129 south-east of Morocco (Figure 1). Here, the Kem Kem beds form an escarpment around the

130 eastern end of the Anti-Atlas, from near Goulmima in the northwest (C. Underwood pers. comm.

131 2018; see Figure 1) past Erfoud in the north (Wellnhofer \& Buffetaut, 1999; Cavin \& Forey,

132 2004) and along the east, parallelling the Algerian border (C. Underwood pers. comm. 2018).

133 The Kem Kem ends to the west, south of Taouz, thereby in total stretching to about $300 \mathrm{~km}$ of

134 outcrop (C. Underwood pers. comm. 2018; see Figure 1). The Kem Kem is usually mentioned to

135 be Cenomanian in age, as it has been found to match ammonites from the Lower Cenomanian of

136 Bahariya, Egypt (Le Loeuff et al., 2012). However, the age range could span over the Albian-

137 Cenomanian (C. Underwood, pers. comm. 2018), which is closer to the age given to the Algerian

138 Cretaceous Continental Intercalaire (Lefranc \& Guiraud, 1990; Le Loeuff et al., 2012) and to the 
139 fossil-rich Cretaceous 'Continental Intercalaire' beds of Tunisia (Fanti et al., 2016) as well as

140 sauropod bonebeds from Niger (Sereno \& Wilson, 2005). The Kem Kem beds are considered to

141 be made up of two formations (see Figure 1): the fossil-rich lower Ifezouane Formation and the

142 upper Aoufous Formation, rich in ichnofossils (Cavin et al., 2010; Belvedere et al., 2013); also

143 named the lower sandy unit (a braided fluvial system) and the upper marly unit (a coastal

144 lagoon), respectively (Cavin et al., 2010, Belvedere et al., 2013, Mannion \& Barrett, 2013;

145 Ibrahim et al., 2014). Practically all fossil vertebrates originate from the lower Ifezouane

146 Formation (Cavin et al., 2010, C. Underwood pers. comm. 2018). The Continental Intercalaire of

147 Algeria is less studied than the Kem Kem, and the age ranges from Barremian to Turonian.

148 However, most authors set the age of the beds close to the Moroccan border (where our Algerian

149 specimens are supposedly from), to Albian-Cenomanian-Turonian, with the Cenomanian layers

150 being the most fossil-rich (Läng et al., 2013; Benyoucef et al., 2015; Meister et al., 2017). As

151 said before, the labeling, however, of 'Taouz, Algeria' is most likely not correct, as Taouz is

152 situated in Morocco, south of Erfoud, close to the border with Algeria, where many fossils from

153 the southern Kem Kem exposures, towards Ouzina, are collected over a broad expanse, usually

154 in mines around Bagaa (M. Dale, C. Underwood, pers. comm. 2018; Figure 1). Indeed, Taouz,

155 Morocco, is indicated as fossil locality in other Kem Kem fossil vertebrate studies (e.g.

156 Wellnhofer \& Buffetaut, 1999; Cavin et al., 2010; Forey, López-Arbarello \& MacLeod, 2011;

157 Richter, Mudroch \& Buckley, 2013). As the Kem Kem outcrops at present run parallel to the

158 border, the labelling of 'Algeria' is probably still be correct, as the 'Kem Kem' beds extend out

159 across the border (Alloul et al., 2018), however, the specific provenance of these teeth is unclear.

160 Next to the labelling, the colour of the fossils likely confirms the provenance on the labels, as

161 fossils from Bagaa (Taouz) are chocolate brown in colour, and fossils from north of Erfoud show 
162 a range of colours, usually shades of beige and black (C. Underwood, pers. comm. 2018),

163 matching the provenance on the collection reference (see Description).

164 As most of the fossils retrieved from the Kem Kem and equivalent beds from Algeria are found

165 via mining, the provenance is unfortunately usually unclear and only traceable to a regional

166 provenance (Forey \& Cavin, 2007; Rodrigues et al., 2011; C. Underwood, pers.comm).

MATERIALS AND METHODS

170 In this study, eighteen isolated sauropod teeth from the Kem Kem beds and Continental

171 Intercalaire are studied for shape, size, position of wear facets (where applicable) and enamel

172 wrinkling. The four teeth from around Taouz (Morocco) are BSPG 1993 IX 331A, BSPG 1993

173 IX 331B, BSPG 1993 IX 331C, and BSPG 1993 IX 313A, see Figure 2A-D. The ten teeth from

174 Erfoud (Morocco) are labeled PIMUZ A/III 0823, and are given the additional labeling of a, b, c,

175 etc., for convenience, see Figure 3A-J. The four Algerian specimens are BSPG 1993 IX 2A,

176 BSPG 1993 IX 2B, BSPG 1993 IX 2C, and BSPG 1993 IX 2D, see Figure 2E-H. Measurements

177 were taken with a caliper to mm scale. For imaging, the teeth were photographed using normal

178 and macro settings. Scanning Electron Miscroscopy (SEM) pictures were taken of the Munich

179 sample at the Zoologisches Institut in Munich to obtain a detailed view of the enamel wrinkling

180 patterns. SEM images were not possible to obtain for the Zürich sample. The specimens were

181 examined using a LEO 1430VP SEM. In this study, the proposed dental orientations of Smith

182 and Dodson (2003) are followed. The Slenderness Index (SI, sensu Upchurch, 1998) was

183 measured for each crown tooth by dividing the apicobasal length by the mesiodistal width in the

184 middle of the crown. The Compression Index (CI, sensu Díez Díaz, Tortosa \& Le Loeuff, 2013) 
185 was measured for each tooth by dividing the labiolingual width by the mesiodistal width in the

186 middle of the crown. The abrasion stages of the functional dentition proposed by Saegusa \&

187 Tomida (2011) and Wiersma \& Sander (2016) will be assessed for each tooth in order to assess

188 possible tooth position in the toothrow. The angles of the wear facets were measured with respect

189 to the labiolingual axes of the teeth. See Table 1 for all tooth measurements.

190

191 The studied sample was compared with teeth from other sauropod taxa in a quantitative approach

192 by multivariate analysis. The comparative tooth sample is measured by first hand observations (i.

193 e., the Lo Hueco, Massecaps, Ampelosaurus, Fox-Amphoux-Métisson sample, Patagosaurus,

194 Lapparentosaurus) as well as from literature, where SI and CI were reported or could be

195 confidently measured or estimated, and a minimum sample size of three tooth specimens was

196 reached (Upchurch \& Barrett, 2000; Barrett et al., 2002; Carpenter \& Tidwell, 2005; Apesteguía,

197 2007; Freire, Medeiros \& Lindoso, 2007; Díaz et al., 2012a,b; Díez Díaz, Tortosa \& Le Loeuff,

198 2013; Díez Díaz, Ortega \& Sanz, 2014; Holwerda, Pol \& Rauhut, 2015; França et al., 2016;

199 Averianov \& Sues, 2017). Taxa from different periods and palaeobiogeographic origins were

200 included where possible. A total of 102 teeth were grouped by taxon, if possible, or sorted by

201 morphotype, finally creating 17 different groups. Both damaged/worn as well as unworn teeth

202 were used, due to paucity of sample size. See Supplementary Table for this data. Differences in

203 SI and CI ratios were tested amongst groups through statistical analyses. The shape of the cross

204 section and the number, angle and size of the wear facets were not considered for this purpose

205 because these features may be more related to other functional factors (i.e., tooth position, stage

206 of tooth wear) rather than a taxonomic factor. Due to the small sample size, the non-normal

207 distribution and the non-homoscedastic variances amongst sample groups, the non-parametric 
208 multivariate one-way PERMANOVA test was performed, followed by post-hoc tests assessing 209 differences for each pair of groups (Hammer \& Harper, 2006). The analysis was implemented

210 using PAST v3.20 (Hammer, Harper \& Ryan, 2001). Finally, the tooth groups were depicted in a

211 dispersion plot, together with additional taxa for which sample size was too small to be included

212 in the statistical analyses (see Discussion).

213

RESULTS

215

\section{Morphological description}

218 Moroccan sample: Taouz

BSPG 1993 IX 331A (Figure 2A)

220 The crown of this chocolate- to reddish-brown coloured, apicobasally elongated tooth is more or 221 less cylindrical. It tapers towards the apex, both mesiodistally and labiolingually. The labial side

222 is strongly convex, the lingual side is straight to concave. The convexity increases towards the 223 apex as the distal $1 / 3$ rd bends more strongly towards the lingual side. The tooth has an almost

224 circular cross section at the base of the crown, becoming slightly more flattened in the 225 labiolingual direction apically. It has a SI of 4.31 and a CI of 0.85 (see Table 1). Two distinct 226 wear facets are present on the lingual and the apical side of the tooth (F2 abrasion stage). The

227 lingual wear facet has an angle of almost 90 degrees with respect to the labiolingual axis. As no 228 mesial and distal wear facets are present this tooth was probably located anteriorly in the upper 229 jaw (premaxilla). A polished surface is found on the labial side of the crown. Either damage or 230 wear is present on the mesial and distal edges on the carinae, exposing the dentine. The enamel 
231 wrinkling pattern is more pronounced on the labial side than on the lingual side of the tooth (see

232 Figure 4A-B). On the labial as well as the lingual side, the pattern is more pronounced in the

233 middle of the tooth, and fades out slightly toward the apex and the base. The labial enamel

234 wrinkling pattern consists of frequently anastomosing, sinuous grooves and crests of varying

235 width with a general apicobasal orientation. Grooves and crests are discontinuous; crests are

236 often interrupted by pits and islets. The crests are rounded to triangular in shape. The distribution

237 of crests and grooves is roughly equal. Compared to the other teeth, excepting BSPG 1993 IX

$238331 \mathrm{~B}$, the crests protrude sharply, and the grooves are relatively deep. On the lingual side, more

239 pits are present, and the grooves and crests appear slightly less rounded in shape, but retain their

240 apicobasal orientation. The grooves appear more shallow on the lingual side.

242 BSPG 1993 IX 331B (Figure 2B)

243 This unworn tooth has the same colour and enamel texture as BSPG 1993 IX 331A. It curves

244 towards the lingual side, with the labial side slightly more convex on the upper half, resulting in

245 a labiolingually tapering apex. The tooth crown is convex toward the distal side, tapering to a

246 mesiodistally narrow apex. The tooth is generally distally inclined, however the apex curves

247 slightly towards the mesial side. It has an oval cross section at the base, which becomes "lemon-

248 like" (sensu Díez Díaz et al., 2013) at the apex due to the presence of pronounced carinae on the

249 mesial and distal edges. Its SI is 2.61 and the CI 0.77 , see Table 1 . The carina on the distal side is

250 slightly more pronounced and continues further basally than the one on the mesial side. The apex

251 contains a polished surface on the mesial side.

252 The wrinkling is similar to BSPG 1993 IX 331A, however, due to the unworn state of BSPG

2531993 IX 331B, it is more pronounced. The enamel wrinkling pattern consists of sharply 
254 protruding, angular, narrow and discontinuous grooves (see Figure 4C-D). The wrinkling on the

255 lingual side is more pronounced than the labial side, and also appears slightly more rounded.

256 Although it is fully developed, the crown lacks wear facets, and the root does not seem to have

257 any resorption, as in the F1 abrasion stage proposed by Wiersma \& Sander (2017). This, together

258 with the coarse enamel pattern of the crown (Figure 4C-D), with no signs of abrasion by

259 occlusion, indicates that this was probably a recently erupted (unused) tooth. Due to this we

260 cannot hypothesize the placement of this tooth in the jaw. This specimen differs from the other

261 teeth in this study by the strong curvature of the crown, and its low SI ratio. This can be

262 attributed to a distal (posterior) placement of the tooth in the jaw, as for example is seen in the

263 nearly complete tooth row of Giraffatitan (MB.R.2181.21), Sarmientosaurus (Martinez et al.,

264 2016), and Abydosaurus (Chure et al., 2010). In addition, and because of its size, it probably

265 belonged to a juvenile individual.

266

267 BSPG 1993 IX 331C (Figure 2C)

268 This chocolate to reddish-brown coloured tooth differs from the first two Kem Kem teeth, in that

269 it is rather straight both labially and lingually, shows little tapering and has a distinctive enamel

270 wrinkling pattern. The apex shows tapering due to labial and lingual wear facets, and only a

271 slight apical mesiodistal tapering is present. A slight curvature towards the lingual side is

272 present. The base and middle of the tooth is oval in cross section; the apex shows a slightly more

273 elliptical shape. It has a SI of 4.11 and a CI of 0.83 , see Table 1.

274 Four wear facets are present on the tooth, one on each of the labial, lingual, mesial, and distal

275 surfaces, respectively. The lingual wear facet is angled at around 60 degrees with respect to the

276 labiolingual axis. The labial wear facet is angled at almost 90 degrees with respect to the 
277 labiolingual axis. Both the mesial and distal wear facets are more pronounced on the lingual side,

278 and are positioned basal to the lingual wear facet. They appear almost parallel to the tooth's main

279 axis. The number and development of the wear facets indicate that this tooth is between the F4

280 and F5 abrasion stages, with an important tooth-to-tooth contact. The food-to-tooth contact

281 seems to not be as important, as the crown enamel is not as worn as in other specimens of this

282 sample (see e.g. BSPG 1993 IX 313A). Due to the higher development of the lingual wear facet

283 and the placement of the mesial and distal ones, this tooth was probably located in the maxilla.

284 The enamel of BSPG 1993 IX 331C is ornamented with thick mesiodistally oriented sharply

285 protruding ridges and relatively wide grooves. At about two thirds of the apicobasal height, the

286 grooves slope towards the base from the mesial and distal edges at an angle of about 45 degrees,

287 and meet in the midpoint. Towards the base, the ridges become more horizontally positioned.

288 Some grooves seem to be connected, forming a chevron-like morphology. This wrinkling pattern

289 is also seen in PIMUZ A/III 0823j. Some pits are visible in the apex, probably due to a diet with

290 some grit content.

291 The four wear facets of BSPG 1993 IX 331C are not seen in similar shapes in any of the other

292 teeth. Moreover, the deep grooves of the enamel wrinkling on the labial and lingual sides of the

293 tooth do not resemble any taphonomic patterns as described by King et al. (1999), but this does

294 not rule out taphonomic processes completely. However, the peculiar pattern is also seen in

295 PIMUZ A/III 0832j, therefore, it is probably natural.

296

297 BSPG 1993 IX 313A (Figure 2D)

298 The upper half of this chocolate-brown coloured, worn tooth crown is inclined towards the

299 lingual side, with the labial side curving convexly, and the lingual side curving concavely. The 
300 apex tapers mesiodistally, and the mesial side of the tooth inclines distally, creating a convex

301 mesial apical end. The tooth has an oval cross-section at the base, becoming more "lemon-like"

302 (sensu Díez Díaz et al., 2013) towards the apex due to the presence of protruding carinae on the

303 mesial and distal edges. The carina on the distal edge continues further towards the base than the

304 carina on the mesial edge. Its SI and CI are 3.35 and 0.76 , respectively, see Table 1.

305 The apex contains one wear facet on the lingual side, angled at around 75 degrees with respect to

306 the labiolingual axis of the tooth. The presence of only one wear facet, the occlusal one, groups

307 this tooth within the F2 abrasion stage. Due to this, this tooth was probably placed anteriorly in

308 the upper jaw (premaxilla).

309 The enamel appears smooth, except for thin apicobasally-oriented discontinuous grooves, (see

310 Figure 4E-F).

311

312 Moroccan sample: Erfoud

313 PIMUZ A/III 0823a (Figure 3A)

314 This reddish-brown worn tooth crown is apicobasally straight in lingual and labial view. Only at

315 the apex, in labial view, does the tip taper very slightly to the distal side. In both mesial and

316 distal views, the tooth is seen to curve towards the lingual side, showing a moderate convexity on

317 the labial side, and an equally moderate concavity on the lingual side; also seen in BSPG 1993

318 IX 331A. The width at the base is only slightly higher than at the middle of the crown, showing a

319 moderate mesiodistal tapering towards the apex. The cross-section of the tooth is oval to

320 elliptical at the base, to oval to possibly lemon-shaped at the apex. The carinae are not

321 pronounced on this tooth, therefore the apical lemon-shaped cross-section is not clear. The 
322 carinae on both sides of the tooth appear worn. This tooth has a SI value of 4.92 and a CI value 323 of 0.58 , see Table 1.

324 Labiolingual tapering towards the apex is caused by the presence of a round to oval lingual wear

325 facet (meaning a F2 abrasion stage). This could mean that this tooth could have been a

326 premaxillary one.

327 The enamel wrinkling pattern is not well-preserved, possibly due to abrasion of the tooth. Only

328 faintly reticulate wrinkling is seen on mostly the labial side of the tooth. This pattern could be a

329 worn enamel wrinkling type similar to that of the more unworn BSPG 1993 IX 331A and BSPG

3301993 IX 331B. No protruding ridges or deep prominent grooves are present in the enamel

331 wrinkling pattern of this tooth.

332

333 PIMUZ A/III 0823b (Figure 3B)

334 This worn, grey to beige coloured tooth displays a unique morphology amongst the tooth sample, 335 as it is a relatively apicobasally short, mesiodistally wide tooth, with a D-shaped cross-section, 336 representing more a general non-neosauropod eusauropod tooth shape (though this feature also 337 exists in basal titanosaurs); Barrett and Upchurch, 2005; Holwerda et al., 2015). In labial and 338 lingual view, the tooth is apicobasally straight at its lower half, showing a similar mesiodistal 339 width at the base as at the middle. The tooth then tapers mesiodistally at its upper half, and also 340 tapers slightly towards the distal side. Moreover, in lingual view, the upper half of the crown,

341 towards the apex, is slightly mesiodistally constricted, giving the tooth a pear-shaped

342 appearance. In mesial and distal view, the tooth curves towards the lingual side, creating a

343 convex labial and concave lingual side. The cross-section is oval at the base, to D-shaped at the 344 apex. The SI is 2.38 and the CI 0.69 , see Table 1. 
345 Both carinae are worn, exposing dentine on both sides, and a prominent oval wear facet is

346 present on the lingual side (F2 abrasion stage). This tooth could have been a premaxillary one.

347 Another worn surface is present on the apex of the labial surface, where the enamel is worn away

348 to expose the dentine.

349 The enamel wrinkling consists of rugose, protruding, continuous anastomosing ridges, which are

350 flattened by wear and/or abrasion throughout. Between these ridges, discontinuous grooves and 351 pits are visible.

352

353 PIMUZ A/III 0823c (Figure 3C)

354 The crown of this well-preserved, unworn tooth is black, whilst the root is cream-coloured to

355 beige. The crown is more or less apicobasally straight in labial and lingual view, however a faint

356 convexity is seen on the medial side, showing a curvature of the entire tooth, from root to apex,

357 towards the distal side. Towards the apex the crown tapers sharply, creating a triangular apical

358 tip. In mesial and distal view, there is only a faint convexity visible on the labial side, whereas

359 the lingual side remains apicobasally straight. The cross-section at the base is oval, and the cross-

360 section at the apex is lemon-shaped (sensu Díez Díaz, Tortosa \& Le Loeuff, 2013). It presents a

361 SI of 3.78 and a CI of 0.67 , See Table 1.

362 As no wear facets are present, this tooth has a F1 abrasion stage. No more information about its

363 placement in the jaw can be deduced. Both carinae are well-preserved as sharply protruding

364 ridges, where the distal carina is more pronounced than the mesial, and shows a faint sinusoidal

365 curvature. Furthermore, the distal carina shows ridges inclining from the apicobasally oriented

366 wrinkling towards the carina, creating denticle-like structures, or pseudodenticles (Bonaparte,

367 Riga, Apesteguia 2006). The enamel wrinkling consists of rugose, discontinuous, sinusoidal, 
368 rounded protrusions and islets, which are intersected by shallow but broad anastomosing grooves

369 and pits. The enamel is most pronounced on the lingual side, whilst the labial side shows a

370 polished surface on the upper half of the crown, where the wrinkling is worn away. This tooth

371 was probably used before it was lost, despite the lack of wear facets, because of its labial

372 polished surface (indicating food-to-tooth contact).

373

374 PIMUZ A/III 0823d (Figure 3D)

375 This reddish to chocolate-brown, worn and polished tooth crown is apicobasally straight in labial

376 and lingual view. In labial view, the tooth is more rectangular in shape, whilst in lingual view,

377 the mesiodistal width increases from the base towards the middle, after which it tapers towards

378 the apex. The apex of the crown inclines slightly towards the distal side, especially in lingual

379 view. In labial view, two grooves are present, the distal of which is slightly displaced towards the

380 middle of the tooth. In mesial and distal view, the labial side is mildly convex, and the lingual

381 side is more apicobasally straight. The cross-section from base to apex remains similar, being

382 oval to elliptical, without protruding carinae on mesial and distal sides. The SI is 2.33 and the CI

383 0.67, see Table 1.

384 Symmetrical, oval wear facets are present on the lingual and labial apices. The presence of both

385 labial and lingual wear facets in the same tooth is an interesting feature that has not been

386 considered in the five abrasion stages (Wiersma \& Sander, 2017). García and Cerda (2010)

387 described several apical wear patterns from a sample of titanosaurian teeth from Argentina, and

388 the morphology of the crown and wear facets of PIMUZ A/III $0823 \mathrm{~d}$ is highly similar to the

389 tooth MPCA-Pv-55 (fig. 5.4). The apex of these teeth (with both labial and lingual apical wear

390 facets) is usually straight and perpendicular to the apicobasal axis of the crown, and the 
391 inclination and development of both wear facets is normally different. García \& Cerda (2010)

392 suggested that the presence of both a labial and a lingual wear facet on the same tooth could be

393 related to the position of the teeth on the tooth row, the occlusal pattern, and the replacement of

394 the opposite teeth (see García \& Cerda, 2010, fig. 7, for a more graphic explanation of this

395 hypothesis). The absence of mesial and distal wear facets suggests that it was probably anteriorly

396 located in the dentary or (pre)maxilla (it is not possible to be more accurate, as both wear facets

397 are equally developed). The mesial and distal sides of the apex do not taper, which further adds

398 to the rectangular appearance of the tooth. The mesial and distal carinae are worn down to

399 smooth, polished ridges, however, the dentine is not exposed.

400 The enamel wrinkling pattern is mostly polished away by (food-to-tooth or taphonomic)

401 abrasion, and only at the base of the labial and lingual sides a faint wrinkling is present. This

402 consists of rounded, anastomosing protrusions, giving a pebbly textural shape, with wide but

403 shallow grooves and pits in between. At the base of the carinae, the wrinkling becomes slightly

404 more rugose, showing angular protrusions angling at $\sim 30$ degrees with respect to the apicobasal

405 axis, towards the carinae, with deep wide grooves running parallel to these.

406

407 PIMUZ A/III 0823e (Figure 3E)

408 The crown of this greyish-brown tooth tapers gently towards the apex in labial and lingual view, 409 and inclines slightly towards the distal side. In labial and lingual view, the tooth crown is

410 apicobasally straight. In mesial and distal view, the tooth is labially strongly convex, but

411 lingually only mildly concave. The apex tapers to a point labiolingually. The cross-section at the

412 base is elliptical to cylindrical, whilst the apex is more D-shaped to elliptical. It has a SI of 4.11 
413 and a CI of 0.78 , see Table 1 . Both carinae are worn, showing marginal grooves where dentine

414 almost appears through the enamel.

415 A large oval wear facet is present on the lingual apical side. However, the labial side also shows

416 a less pronounced wear facet, symmetrically placed to that of the lingual side. This tooth was

417 probably placed anteriorly in the upper part of the mouth (possibly premaxilla), as can be

418 deduced from the more developed lingual wear facet and the absence of mesial and distal facets.

419 The poor development of the labial wear facet indicates that its lower new opposite tooth

420 probably erupted only shortly prior to its loss. We consider a F2 abrasion stage to be appropriate

421 for this tooth, due to the poor development of the labial wear facet, and its placement in the

422 premaxilla (because of the absence of mesial and distal wear facets).

423 The enamel wrinkling pattern is finely reticulate, with a symmetrical distribution of small

424 rounded protrusions surrounded by thin grooves. However, at the base of the crown, the enamel

425 shows deep continuous grooves interspersed with pits, whilst the protrusions are worn away. Part

426 of the enamel at the root is damaged or gone.

427

$428 \quad$ PIMUZ A/III 0823f (Figure 3F)

429 This black, smooth, tooth crown shows traces of red sediment. In labial and lingual views, the

430 lower half of the tooth crown is straight, after which it shows a strong inclination towards the

431 distal side, giving the mesial apical half a convex, and the distal apical half a straight to concave,

432 shape. In mesial and distal views, the tooth is rather apicobasally straight, only a faint labial

433 convexity and lingual concavity is seen. The cross-section at the base is round to elliptical, and

434 more cylindrical to a very faint lemon-shape (due to the carinae) at the apex. Apically, the tooth

435 tapers to a sharp tip which is inclined distally. The SI is 4.75 and the CI is 0.88 . Both mesial and 
436 distal carinae show a prominent but smooth ridge protruding towards mesial and distal sides on

437 the apical half of the crown, the lower half of the crown does not show carinae.

438 As no apical wear facets are present we consider this tooth to show a F1 abrasion stage. Due to

439 this, the placement of this tooth in the snout cannot be hypothesized. The enamel is completely

440 smooth, suggesting, together with the lack of clear wear facets, that this tooth was relatively

441 unused and unworn.

442

443 PIMUZ A/III 0823g (Figure 3G)

444 This grey to reddish brown tooth crown follows the same general morphology as PIMUZ A/III

445 0823f, in that the lower half of the crown is apicobasally straight in both labial and lingual views,

446 as well as in mesial and distal views. The upper half of the crown bends towards the distal side,

447 providing the mesial side with a convex curvature. The apex tapers to a sharp tip in labial and

448 lingual view, as well as in mesial and distal view. Both mesial and distal carinae are present,

449 which are prominently but smoothly protruding at the apical half of the crown. The cross-section

450 is elliptical at the base to strongly lemon-shaped at the apex. This tooth has a SI value of 4.83

451 and a CI value of 0.83 , see Table 1.

452 An apicobasally-elongated, mesiolabially-oriented wear facet, as well as an equally elongated,

453 distallingual wear facet is present, giving the apical half of the crown a more constricted shape,

454 and creating a faint buttress at the base of the mesial and distal constriction. Finally, a faint,

455 small, round apical wear facet is present. The presence of these three wear facets place this tooth

456 in a F4 abrasion stage, as the apex is already gently rounded. This tooth probably was placed in

457 the maxilla. The slight displacement of both mesial and distal wear facets indicate that this tooth 
458 was rotated. The enamel is completely smooth, however, apicobasal striations in the enamel are

459 present on the labial apical side of the tooth.

460

461 PIMUZ A/III 0823h (Figure 3H)

462 The smallest tooth of the sample, this reddish-brown crown shows a similar morphology to

463 PIMUZ A/III 0823f and PIMUZ A/III 0823g. The crown is straight in labiolingual and

464 mesiodistal views, with only the mesial apical end inclining towards the distal side in

465 labiolingual view. The apex tapers to a sharp tip. The cross-section is elliptical to cylindrical at

466 the base and at the apex. The SI is 4.33 and the CI is 0.75 , see Table 1.

467 The tooth is completely smooth and nearly unworn; only a small, circular, apical wear facet is

468 present (F1-F2 abrasion stage). This information is not sufficient to propose its likely placement

469 in the snout. Due to its small size and unworn state, this tooth might originate from a juvenile.

470

$471 \quad$ PIMUZ A/III 0823i (Figure 3I)

472 This rectangular, red tooth is the second smallest of the Erfoud sample. It has a rectangular

473 shape, showing almost no tapering in labial and lingual view, and only a slight apical tapering in

474 mesial and distal view. In mesial and distal view, the labial side is mildly convex and the lingual

475 side is mildly concave. The cross-section is oval at the base to oval to lemon-shaped at the apex.

476 It has a SI of 3.82 and a CI of 0.73 , see Table 1.

477 The labial apical side shows a high-angled, oval wear facet, whilst a low-angled elongated wear

478 facet is present on the lingual side, which stretches to halfway down the apicobasal length of the

479 crown. This tooth presents the same condition as PIMUZ A/III 0823d, with both labial and

480 lingual apical wear facets. As the apical labial wear facet is more developed, this tooth may have 
481 been placed in the lower jaw. The absence of mesial and distal wear facets suggests that it was

482 probably anteriorly located in the dentary. The enamel of the tooth is completely smooth.

483

484 PIMUZ A/III 0823j (Figure 3J)

485 This dark brown to black tooth tapers gently towards the apex from the base, whilst being 486 slightly mesiodistally constricted at around the middle. The labial side is convex, whilst the

487 lingual side remains apicobasally straight. Both mesial and distal carinae are present as smooth

488 ridges which do not protrude. The cross-section is elliptical, both at the base as well as at the

489 apex. It presents a SI value of 3.78 and a CI value of 1.11 , see Table 1.

490 The upper half of the tooth crown is polished. However, only on the lingual side, a low angled

491 wear facet is present. Both at the mesial and distal apical sides, a low-angled, oval, polished

492 surface is present as well, indicating tooth overlapping (F4 abrasion stage, as the crown apex is

493 rounded). The location and development of these three wear facets indicate that this tooth was

494 probably located in the maxilla.

495 The enamel wrinkling pattern is only visible at the base of the tooth, as, similar to BSPG 1993 IX

$496331 \mathrm{C}$, there is a mesiodistally-positioned, chevron-like pattern of deep wide grooves and ridges,

497 which disperse towards the carinae.

498

499 Algerian sample

500 BSPG 1993 IX 2A (Figure 2E)

501 The tooth is covered in black enamel, and has a reddish-brown base. The crown is apicobasally

502 straight. The mesial and distal sides taper strongly towards the apex, whereas the labial and

503 lingual sides taper slightly. The mesial side, however, shows a slight convexity, and curves 
504 towards the distal side, which is straight apically. The tooth is mesiodistally widest at the middle,

505 after which it tapers towards the apex. Carinae are present on the mesial and distal edges of the

506 upper third of the crown, as smooth protruding ridges. The carina on the distal side shows a

507 slightly sinusoidal curvature at about halfway of the apicobasal length of the tooth, which is also

508 seen in PIMUZ A/III 0823c. The distal carina reaches slightly further basally. The cross-section

509 at the base is oval, becoming lemon-like at the apex due to the carinae (sensu Díez Díaz, Tortosa

$510 \&$ Le Loeuff, 2013). The SI is 4.35 and the CI 0.78, (see Table 1).

511 A wear facet is present on the lingual side, angled at around 50 degrees with respect to the

512 labiolingual axis. The presence of only one wear facet, the occlusal one, groups this tooth within

513 the F2 abrasion stage. As this facet is located lingually, and there are no mesial and distal wear

514 facets, this tooth was probably placed in the maxilla.

515 The apical part of the labial side also shows a polished surface, as in PIMUZ A/III 0823c. The

516 enamel wrinkling pattern on both the labial and lingual sides consists of apicobasally-oriented

517 grooves and ridges, which are less broad and more sinuous on the labial side than on the lingual

518 side (see Figure 4G-H). While unworn, was probably similar to the crown enamel of BSPG 1993

519 IX 2B (Figure 4I-J), but it has been worn by tooth-to-food contact (like BSPG 1993 IX 313A,

520 Figure 4E-F). The enamel on the labial side is slightly thicker than on the lingual side.

BSPG 1993 IX 2B (see Figure 2F)

523 This worn tooth is grey to beige in colour. The tooth is curved lingually, with the labial side

524 convex, and the lingual side concave. This curvature increases towards the apex. A very slight

525 mesiodistal tapering can be seen at the apical part of the crown, however the tooth appears

526 rectangular when observed from the labial and lingual side. Labiolingual tapering appears due to 
527 the presence of a labial and lingual wear facet intersecting at the apex. The lingual side of the

528 tooth is relatively flat in the mesiodistal direction when compared to the labial side. This gives

529 the tooth an oval cross section at the base, becoming D-shaped toward the centre, and more

530 cylindrical to lemon-shaped apically due to the presence of carinae. Carinae are present on the

531 mesial and distal edges, although the distal carina is more pronounced and continues further

532 basally. It has a SI of 3.65 and a CI of 0.71 , (see Table 1).

533 Two distinct wear facets are present on BSPG 1993 IX 2B, one on the labial and the other on the

534 lingual side. The labial wear facet is larger (almost $15 \mathrm{~mm}$ in apicobasal length), and angled

535 toward the mesial side. The labial wear facet is angled at around 72 degrees with respect to the

536 labiolingual axis of the crown. The lingual wear facet is smaller. It cuts the labiolingual axis at

537 almost 90 degrees. This tooth presents the same condition as PIMUZ A/III 0823d and PIMUZ

538 A/III 0823i, with both labial and lingual apical wear facets. As the apical labial wear facet is

539 more developed in BSPG 1993 IX 2B, this tooth may have been placed in the lower jaw. The

540 absence of mesial and distal wear facets suggests that it was probably anteriorly located in the

541 dentary.

542 The enamel wrinkling pattern consists mainly of apicobasally-oriented, sinuous grooves and

543 ridges. The ridges are sharply protruding and are triangular in shape (see Figure 4I-J).The enamel

544 wrinkling pattern of BSPG 1993 IX 2B appears quite similar to BSPG 1993 IX 331A, BSPG

5451993 IX 331B, and the labial side of BSPG 1993 IX 2A. The enamel wrinkling of BSPG 1993

546 IX 331A and of BSPG 1993 IX 331B is slightly more pronounced than the enamel wrinkling of

547 BSPG 1993 IX 2B, a difference perhaps caused by greater wear on the latter. A noteworthy

548 difference between the enamel wrinkling patterns of this tooth and all other teeth from this 
549 sample is that the enamel wrinkling is more pronounced on what seems to be the lingual side,

550 instead of the labial side.

551

552 BSPG 1993 IX 2C (Figure 2G)

553 This grey to beige coloured tooth is badly preserved and largely covered with reddish sediment.

554 The crown is fairly straight apicobasally, and tapers apically (mesiodistally as well as

555 labiolingually). The mesial apical side shows a curvature towards the distal side, as seen in

556 BSPG 1993 IX 2A. From the base to the middle, the width of the crown expands slightly

557 labiolingually, after which it tapers to the apex. This expansion mainly seems to occur on the

558 convex (probably labial) side, and is also seen in BSPG 1993 IX 2A. The distal edge shows faint

559 traces of a carina but that cannot currently be accurately determined. The cross-section at the

560 base is slightly oval, becoming almost circular at the middle of the crown, and then becoming

561 more lemon-like apically due to the presence of carinae. The SI is 4.09 and the CI is 0.87 , (see

562 Table 1).

563 A possible wear facet can be seen on the labial side, cutting the labiolingual axis of the crown at

564 a low angle (35 degrees), so it was probably at a F2 abrasion stage. The absence of mesial and

565 distal wear facets, and the labial position of the one present, indicate that this tooth probably

566 belonged to the anterior part of the dentary. Because of the damaged state of this tooth, no SEM

567 pictures were taken.

568

569 BSPG 1993 IX 2D (Figure 2H)

570 This reddish-brown coloured crown tapers mesiodistally towards the apex, as well as

571 labiolingually, resulting in a sharp apical tip. The labial side is convex, whilst the lingual side is 
572 more concave. The upper third of the crown shows stronger mesiodistal tapering on the mesial

573 side. Distinctly protruding carinae are present on the mesial and distal edges of the crown. The

574 mesial carina is slightly more distinct due to the curvature of the mesial apical part, however, it

575 only runs halfway along the tooth towards the base, whereas the distal carina continues further

576 basally, to the upper 3/4th of the tooth. The tooth has an oval cross section at the base, becoming

577 strongly lemon-shaped apically due to the distinct carinae. It presents a SI of 3.62 and a CI of

$578 \quad 0.71$, (see Table 1).

579 Wear facets are not present (F1 abrasion stage), so its position on the snout cannot be deduced.

580 The enamel is smooth except for some pits (see Figure 4K-L). This feature is interesting, not

581 only because this tooth is the one that has the most worn crown enamel, but also for the presence

582 of pits on it. The individual probably fed on low vegetation, with a significant quantity of grit.

583 This tooth had clearly been used for feeding, but occlusion features are not present, so it was

584 probably located anteriorly in the snout, with its opposite tooth unerupted throughout its

585 functional life.

586

587 DISCUSSION

588

589 Systematic discussion and comparisons

590 The tooth sample from northwestern Africa shares the presence of mesial and distal margins

591 extending parallel to each other along almost the entire length of the crown with neosauropod

592 (diplodocoid and titanosauriform) sauropods, together with the absence of a mesiodistal

593 expansion at the base of the crown (Calvo, 1994; Upchurch, 1995, 1998; Salgado \& Calvo, 1997;

594 Wilson \& Sereno, 1998; Upchurch \& Barrett, 2000; Barrett et al., 2002; Wilson, 2002; 
595 Upchurch, Barrett \& Dodson, 2004). These teeth also share with diplodocoids and titanosaurs the

596 loss of some plesiomorphic features of Sauropoda, which are retained in some, but not all, basal

597 titanosauriforms (e.g. Giraffatitan, Euhelopus), such as the presence of a lingual concavity with a

598 median ridge, and labial grooves (Upchurch, 1998; Barrett et al., 2002).

600 The general crown outline is similar in all the teeth of the sample: parallel-sided crowns showing 601 slight labiolingual compression with mesial and distal carinae, which express a higher amount of 602 protrusion in BSPG 1993 IX 331B, BSPG 1993 IX 2A, BSPG 1993 IX 2D, PIMUZ 0823c and 603 PIMUZ A/III 0823h. The labiolingual compression (seen in apical view) is more conspicuous in

604 the Algerian teeth, though PIMUZ A/III 0823a from Erfoud, Morocco, also shows this amount of 605 compression. BSPG 1993 IX 331B and BSPG 1993 IX 2D, PIMUZ A/III 0823d, PIMUZ A/III 606 0823h, PIMUZ A/III 0823i present a different crown morphology from the rest of the sample 607 (see below). However, this difference in the crown morphology between these teeth and the rest 608 of the sample could be due to different positions in the tooth row, as occurs in most eusauropods 609 and other sauropodomorphs (e.g. Carballido \& Pol, 2010; Chure et al., 2010; Holwerda et al., 610 2015; Martinez et al., 2016; Mocho et al., 2016, Carballido et al., 2017; Wiersma \& Sander, 611 2017). Lingual buttresses seen in titanosauriforms from the Lower Cretaceous of Japan (Barret et 612 al., 2002), South Korea (Lim, Martin \& Baek, 2001), in Giraffatitan (Janensch, 1935), and in 613 Astrodon (Carpenter \& Tidwell, 2005), or circular bosses as seen in Euhelopus (Barrett \& Wang, 614 2007; Poropat \& Kear, 2013) a possible macronarian from the Upper Jurassic of Portugal

615 (Mocho et al., 2017), and an unknown (possible euhelopodid) titanosauriform from the 616 Barremian of Spain (Canudo et al., 2002) are not seen in any of our Moroccan or Algerian tooth 617 samples. Neither do the Algerian and Moroccan tooth samples show mesial and distal buttresses 
618 such as in an isolated tooth from the Santonian of Hungary (Ösi, Csiki-Sava \& Prondvai, 2017).

619 Moreover, diplodocoid pencil-like or needle-like teeth as in Limaysaurus (Calvo \& Salgado,

620 1995; Salgado et al., 2004) are not found in this sample either. In addition, two further enamel

621 types can be found in the sample: rugosely or reticulately wrinkled (BSPG 1993 IX 331A, 331B,

622 331C, PIMUZ A/III 0823a,b,c,e, BSPG 1993 IX 2B and 2C) or smooth (BSPG 1993 IX 313A,

623 PIMUZ A/III 0823d,f,g,h,i, BSPG 1993 IX 2A, and 2D) enamel. The differences between more

624 rugose and more reticulate wrinkling in the enamel ornamentation could be due to the wear of

625 the tooth and the diet of the individual animal.

626 Finally, although the CI is similar in both morphotypes, the SI range is wider in the Moroccan

627 Erfoud sample, whilst remaining within a similar range between the Moroccan Taouz and the

628 Algerian sample.

629 After the morphological descriptions and similarities, two main morphotypes could be

630 distinguished, based on shared features of shape, expression of wear facets, carinae and enamel

631 wrinkling. One morphotype, however, may harbour further submorphotypes, which are also

632 discussed, however, without further sampling this could not be proven valid. It should also be

633 noted that the morphotypes proposed here might not always reflect biological morphotypes. The

634 morphotypes are here discussed and compared to other sauropods, including, but not restricted

635 to, biogeographically similar and contemporaneous sauropods (e.g. of Spain, France, northwest 636 and central Africa).

637

638

Morphotype I: BSPG 1993 IX 331A, BSPG 1993 IX 331B, BSPG 1993 IX 313A, BSPG 1993

639

IX 2A, BSPG 1993 IX 2C, BSPG 1993 2D; PIMUZ A/III 0823a, PIMUZ A/III 0823b, PIMUZ 
640

641

642

643

644 This is the most abundant morphotype in the sample. It consists of teeth with high SI $(2,2-4,9)$

645 and CI (0,6-0,9), rugose enamel wrinkling (but see discussion on this), prominent mesial and

646 distal carinae, together with a labial convexity, and a slightly distal inclination of the apex, and a

647 subcylindrical to lemon-shaped cross-section. There are many intra-group specific morphological

648 differences within this morphotype, however as teeth both differ morphologically within one

649

650

651 Wiersma \& Sander, 2016), enamel wrinkling as well as the presence of carinae are taken as the

652 main drivers for comparisons (see Carballido \& Pol, 2010; Holwerda, Pol \& Rauhut 2015).

653 Moreover, enamel wrinkling can be demonstrated to change over ontogeny, with indications that

654 juveniles have smooth, or smoother enamel wrinkling in comparison with adult animals (Fiorillo, 655 1991, 1998; Díaz et al., 2012; Díaz, Suberbiola \& Sanz, 2012; Díez Díaz, Ortega \& Sanz, 2014;

656 Holwerda, Pol \& Rauhut, 2015). As stated above, this abundant Morphotype I arguably still

657 hosts several (sub)morphotypes, which are also discussed below.

658

659

660

661

662

\section{Discussion}

BSPG 1993 IX 331A and BSPG 1993 IX 331B (Figure 2A, 2B) show a different SI, and different CI. However, they share a similar morphology in terms of expression of carinae, labial convexity, and enamel wrinkling pattern, and most likely belong to the same morphotype.

Similarly, PIMUZ A/III 0823a shares the same apicobasal elongation of BSPG 1993 IX 331A, as 
663 well as a worn-down version of the rugose and highly sinuous enamel wrinkling. This reticulate,

664 worn-down version of the rugose type of enamel wrinkling is further found in BSPG IX 1993

665 313A, BSPG IX 1993 2B, as well as in PIMUZ A/III 0823b and PIMUZ A/III 0823e. BSPG

6661993 331A resembles a large Campanian-Maastrichtian titanosaur tooth from Río Negro,

667 Argentina (Garcia, 2013), in having a similar crown-root transition, as well as having high CI

668 and SI ratios ( 0.73 vs 0.85 and 3.73 vs 4.36 for the tooth described by Garcia, (2013) and BSPG

6691993 IX 331A respectively). However, the enamel wrinkling patterns between these two teeth

670 show great differences; the enamel of BSPG 1993 IX 331A shows highly sinuous patterns not

671 visible on the Argentine tooth. The tooth also resembles the cylindrical morphotype with circular

672 cross-section of the southeastern French Campanian-Maastrichtian Fox-Amphoux-Métisson

673 morphotype (FAM 03.06, 03.11, and 04.17; Díaz et al., 2012b, fig. 9). The SI ratios are high in

674 both the Algerian/Moroccan and the French sample ( 4, excepting BSPG 1993 IX 331B). These

675 teeth also display a similar labial convexity, which becomes stronger towards the apex in both

676 the Algerian/Moroccan and the French sample. The enamel wrinkling differs between these two,

677 however, as the Kem Kem teeth show a much more pronounced enamel wrinkling. The

678 apicobasal elongation, slight labial convexity, and presence on most of these teeth of an apically

679 based labial and lingual wear facet, also resembles that of the Late Cretaceous Mongolian

680 Nemegtosaurus (Wilson, 2005). Finally, the moderate tapering (or lack thereof) resembles that of

681 teeth of the Late Cretaceous Alamosaurus from the USA (Kues, Lehman \& Rigby, 1980),

682 although the enamel wrinkling on Alamosaurus is smoother than in the Moroccan/Algerian

683 sample, though apicobasal striations are present on both.

684 Even though the reticulate enamel wrinkling could be a worn-down version of the rugose

685 wrinkling described for this morphotype, BSPG 1993 IX 313A, PIMUZ A/III 0823b and PIMUZ 
$686 \mathrm{~A} / \mathrm{III} 0823 \mathrm{e}$ (Figure 2D, Figure 3B, 3E) slightly deviate from the general shape of this

687 morphotype in displaying a mesiodistally constricted apex in labial and lingual view. A

688 difference in order of tooth row might explain this, as teeth from the mesial side of the toothrow

689 are larger and more robust than teeth from the distal end of the toothrow. This is not seen in

690 titanosaurs (García \& Cerda, 2010), however, it is observed in titanosauriforms (e.g. Giraffatitan

691 MB.R.2181.21; Abydosaurus, Chure et al., 2010). This shape is further seen in more robust

692 (lower SI, higher mesiodistal and labiolingual width) titanosauriform morphotypes, such as the

693 Cenomanian titanosauriform indet. tooth from France, described by Vullo, Neraudeau \& Lenglet,

694 (2007), Astrodon (Carpenter \& Tidwell, 2005), the more robust tooth form of the Late

695 Cretaceous Asian Mongolosaurus (Mannion, 2011), Europatitan from the Barremian-Aptian of

696 Spain (Torcida Fernández-Baldor et al., 2017), the posterior maxillary teeth of the Cenomanian-

697 Turonian Patagonian Sarmientasaurus (Martínez et al., 2016), Ligabuesaurus from the Aptian-

698 Albian of Neuquen, Argentina, (Bonaparte, González Riga \& Apesteguía, 2006) an unnamed

699 titanosaur tooth sample from the Upper Cretaceous Bissekty Fm., Uzbekistan (Averianov \&

700 Sues, 2016), and lastly, the robust types of the Massecaps and Ampelosaurus morphotypes from

701 the Campanian-Maastrichtian of southeastern France (Díez Díaz, Tortosa \& Le Loeuff, 2013).

702 Finally, BSPG 1993 IX 313A, with its strong apical labial convexity, is morphologically similar

703 to both the small tooth type of the Cenomanian-Campanian Chinese Huabeisaurus (D'Emic et

704 al., 2013), as well as the small Campanian-Maastrichtian Atsinganosaurus tooth type from

705 France by sharing a labiolingual compression (CI: 0.76), a high-angled apical wear facet, and

706 lemon-shaped cross section due to the presence of apical carinae (Díez Díaz, Tortosa \& Le

707 Loeuff, 2013; fig. 3, MHN-AIX-PV.1999.22). It also matches Huabeisaurus and

708 Atsinganosaurus in having smooth enamel. One hypothesis for this smooth enamel could be the 
709 tooth-to-food contact, that could have worn a previously more coarse enamel, like the ones of

710 BSPG 1993 IX 331A and BSPG 1993 IX 331B (Figure 4A-D). However, the enamel of BSPG

7111993 IX 313A does not present the conspicuous pits that appear on the enamel of BSPG 1993 IX

712 2D (Figure 4K-L) from the Algerian sample. This could be due to a diet with a greater quantity

713 of grit in the Algerian individual, as happens in many sauropods, especially the ones that fed in

714 the lower levels of the trees (Fiorillo, 1998; Upchurch \& Barrett, 2000; García \& Cerda, 2010).

715 The individual of BSPG 1993 IX 313A may have fed on soft vegetation, as has been suggested

716 for Diplodocus (Fiorillo, 1998).

717 Also included in Morphotype I are BSPG 1993 IX 2A, BSPG 1993 IX 2C, PIMUZ A/III 0823c

718 (Figure 2E, 2G, Figure 3C). These teeth deviate from the general cylindrical and general apical

719 tapering shape of Morphotype I in that they all display a mesiodistally slender base, after which

720 the width increases towards the middle, and then tapers towards the rounded apical tip. This is

721 also arguably seen in Rinconsaurus (Calvo \& González Riga, 2003), as well as in an unnamed

722 titanosaur tooth sample from the Upper Cretaceous Bissekty Formation., Uzbekistan (Averianov

$723 \&$ Sues, 2016), although the latter teeth show a lingual median ridge, which the Moroccan and

724 Algerian samples do not. BSPG 1993 IX 2A and BSPG 1993 IX 2C display a similar low angled

725 lingual wear facet ( $\sim 50$ degrees relative to the labiolingual tooth axis), and both BSPG 1993 IX

726 2A and PIMUZ A/III 0823c show a similar labial polished surface. BSPG 1993 IX 2C is too

727 worn, however the carinae of the well-preserved BSPG 1993 IX 2A and PIMUZ A/III 0823c are

728 prominently present, as mesially and distally offset ridges. Moreover, the distal carina is more

729 developed than the mesial one in both, showing a sinusoidal curvature in distal view, as seen to a

730 lesser extent in Huabeisaurus (D'Emic et al., 2013). Note, however, that the carinae are not as

731 prominent as in Euhelopus (Barrett \& Wang, 2007; Poropat \& Kear, 2013). Furthermore, the 
732 distal carina of PIMUZ A/III 0823c shows pseudodenticles, a feature seen in the Late Jurassic

733 South African Giraffatitan (Janensch, 1935), the Lower Cretaceous Patagonian Ligabuesaurus

734 (Bonaparte, Riga \& Apesteguia 2006), an unnamed titanosauriform from the Early Cretaceous of

735 Denmark (Bonde, 2012), the Late Jurassic French Vouivria (Mannion, Allain \& Moine, 2017),

736 and the Early Cretaceous African Malawisaurus (Gomani, 2005).

737 Furthermore, BSPG 1993 IX 2A resembles the morphotype B of Lo Hueco, Spain (MCCM-HUE

738 2687, (Díez Díaz, Ortega \& Sanz, 2014; fig. 5). Both morphotypes are cylindrical, have a high SI

739 (>4.3), a strong apical distal or medial inclination of the tooth (giving the tooth a far from

740 straight outline) with a high-angled wear facet. Moreover, the enamel wrinkling of BSPG 1993

741 IX 2A matches that of the Lo Hueco morphotype, in that both morphotypes show coarse, but not

742 rugose, discontinuous wrinkling, with smooth longitudinal ridges, although BSPG 1993 IX 2A

743 shows more pronounced enamel wrinkling than Lo Hueco morphotype B.

744 PIMUZ A/III 0823c also resembles Lo Hueco morphotype A, in the general morphology of the

745 crown and its length, its labiolingual compression, and its SI and CI values (see e.g. HUE-685,

746 (Díez Díaz, Ortega \& Sanz, 2014, fig. 2).

747 It could be argued that, due to the differences of BSPG 1993 IX 2A, BSPG 1993 IX 2C, PIMUZ

$748 \mathrm{~A} / \mathrm{III} 0823 \mathrm{c}$ from the rest of Morphotype I, these teeth could be gathered in a separate

749 morphotype, however, as the sample size is low, with only three teeth, further analysis to help

750 distinguish any (sub)morphotypes is not possible and lies outside of the scope of the current

751 study, until a higher tooth sample can be examined. Therefore, although these teeth are discussed

752 as potentially separate, the most parsimonious conclusion is to leave them in Morphotype I.

753 Finally, BSPG 1993 2D, PIMUZ A/III 0823f, PIMUZ A/III 0823g, PIMUZ A/III 0823h are

754 assigned to Morphotype I, although the enamel wrinkling differs from the rugose type (both the 
755 worn and unworn expression of it). BSPG 1993 IX 2D, PIMUZ A/III 0823f, PIMUZ A/III 0823g

756 and PIMUZ A/III 0823h (Figure 2H, Figure 3F, 3G, 3H) all share a smooth enamel type, a strong

757 distal displacement of the apex in labial and lingual view, an acutely tapering, sharp apical tip,

758 and a distally inclined base of 45 degrees. One tooth (PIMUZ A/III 0823h) is likely to be a

759 juvenile tooth. This is interesting, as thus far teeth of juvenile sauropods show a difference in

760 expression of enamel wrinkling, as found by Fiorillo (1991, 1998), Díez Díaz et al. (2012), Díaz,

761 Suberbiola \& Sanz, (2012), Díez Díaz, Ortega \& Sanz, (2014), and Holwerda, Pol \& Rauhut

762 (2015) in several titanosaurian teeth from the Ibero-Armorican Island. The smoothness of enamel

763 wrinkling in juvenile teeth, therefore, could express differently in adults, further supporting the

764 most parsimonious conclusion of including these last teeth in Morphotype I. Barrett et al., (2016)

765 described some juvenile (hatchling or even embryonic) sauropod teeth of

766 titanosauriforms/camarasaurids from the Berriasian of southern France, which match the apical

767 morphology of this Moroccan tooth. However, the Moroccan tooth lacks the basal mesial

768 constriction and the lingual buttress of juvenile teeth described by Barrett et al. (2016). Juvenile

769 teeth are also described by García \& Cerda, (2010) for sauropod embryos from Auca Mahuevo,

770 however these small teeth show a more acutely tapering apical tip than the Moroccan sample.

771 PIMUZ A/III 0823f and PIMUZ A/III 0823h resemble the Spanish Lo Hueco morphotype A in

772 the general morphology of their crowns and their slight apical asymmetry (which could be due to

773 wear). PIMUZ A/III 0823f also reflects the Lo Hueco morphotype A in that it has a similar

774 length, labiolingual compression, and SI and CI values (Díez Díaz, Ortega \& Sanz, 2014). As

775 PIMUZ A/III 0823h probably belonged to a juvenile specimen, the size of this tooth is smaller

776 when compared to the other ones, and this changes the SI and CI values. Juvenile teeth need to 
777 be used with caution when included in comparative studies, especially when using quantitative

778 variables such as the SI and CI (see Statistical Analysis).

779 PIMUZ A/III 0823g is the only tooth with smooth enamel that shows striations on the surface,

780 providing the cross-section with a slightly rhomboid shape, however the strongly protruding

781 carinae also still give a lemon-shaped cross section. Striations are seen on teeth of Huabeisaurus

782 (D’Emic et al., 2013), brachiosaurid teeth from South Korea (Lim et al., 2001), smooth enamel

783 type titanosaur teeth from the Bissekty Fm., Uzbekistan (Averianov \& Sues, 2016), and in

784 combination with smooth enamel, in Atsinganosaurus (though some teeth do display gentle

785 wrinkling on the middle, see Díez Díaz, Tortosa \& Le Loeuff, (2013), as well as in

786 Demandasaurus (Torcida Fernández-Baldor et al., 2011), although the carinae are less

787 conspicuous on the latter taxon. Smooth enamel, in combination with a sharp apex, is further

788 seen in the Albian Karongasaurus from Malawi (Gomani, 2005). Smooth enamel exists on

789 Limaysaurus (Salgado et al., 2004), however this tooth is more needle-shaped than the teeth of

790 the Moroccan/Algerian sample. As these teeth are not worn, the apical morphology differs from

791 the other teeth of Morphotype I, which are all mostly worn apically. However, as worn versus

792 unworn teeth cannot be properly morphologically distinguished with isolated teeth, these are still

793 assigned to Morphotype I.

794 Given the resemblance of Morphotype I to predominantly Cretaceous sauropods, and moreover,

795 given the size and shape range, this morphotype is difficult to assign to any particular group. The

796 size and shape range suggests a titanosauriform origin, as derived titanosaurians usually show a

797 more conservative morphological range (García \& Cerda, 2010). However, given the similarity

798 between some teeth of Morphotype I with those of titanosaurians, it is more likely that both non-

799 titanosaurian titanosauriforms as well as titanosaurians are present in the tooth sample of 
800 Morphotype I, which reflects sauropod postcranial diversity of the Cretaceous of northwest

801 Africa recorded by previous studies, as both titanosauriforms (Mannion \& Barrett, 2013; Fanti,

802 Cau \& Hassine, 2014; Lamanna \& Hasegawa, 2014) as well as derived titanosaurians (Ibrahim et

803 al., 2016) have been reported to be present. Even though some of the teeth resemble more

804 specific groups (e.g. Euhelopus, Huabeisaurus) the general morphotype cannot be assigned to

805 any more specific group. No affinity with other groups (e.g. diplodocids, rebbachisaurids) is

806 found for Morphotype I either.

807

808

Morphotype II: BSPG 1993 IX 331C, BSPG 1993 IX 2B, PIMUZ A/III 0823d, PIMUZ A/III

809

0823i, PIMUZ A/III 0823j

810 General

811 A smaller tooth sample from both the Moroccan and Algerian sample deviates morphologically

812 from Morphotype I. These teeth show a more rectangular morphology, a lack of apical tapering,

813 and distinct labial and lingual wear facets.

\section{Discussion}

815 BSPG 1993 IX 331C and PIMUZ A/III 0823j (Figure 2C, Figure 3J) both show a distinctive

816 enamel wrinkling, not seen in the other teeth of the sample. It displays a 'chevron' pattern on the

817 labial and lingual surfaces, with rugose striations anastomosing towards the carinae. This pattern

818 is arguably present on the labial side of the enamel of another Moroccan Kem Kem sauropod

819 tooth, tentatively (but not conclusively) assigned to rebbachisauridae by Kellner \& Mader

820 (1997). This latter tooth, however, also shows striations (Kellner \& Mader, 1997), which are not

821 seen on BSPG 1993 IX 331C, and PIMUZ A/III 0823j. As Carballido \& Pol (2010) and

822 Holwerda, Pol \& Rauhut (2015) showed, enamel wrinkling on sauropod teeth can be an 
823 autapomorphic diagnostic feature. As both teeth are worn, however, the other morphological

824 features besides enamel wrinkling must be taken into account. The teeth do share morphological

825 similarities in crown shape with the tooth described by Kellner \& Mader (1997), which is

826 apicobasally straight. The rectangular morphology of these teeth, caused by a lack of mesiodistal

827 tapering towards the apex, together with a slightly higher CI due to higher labiolingual

828 compression than the other teeth from the Moroccan/Algerian sample, showing an oval to

829 cylindrical cross-section, is shared with BSPG 1993 IX 2B, as well as PIMUZ A/III 0823d and

830 PIMUZ A/III 0823i (Figure 2F, Figure 3D, 3I). These five teeth further share labial and lingual

831 wear facets, which are symmetrically placed, though in PIMUZ A/III 0823i, as well as in BSPG

8321993 IX 2B, one high-angled and low-angled wear facet is seen, which is characteristic of the

833 Aptian-Albian Nigersaurus (Sereno \& Wilson, 2005; p.166, fig. 5.7; Sereno et al., 2007, Fig. 2).

834 The size of PIMUZ A/III 0823i matches that of Nigersaurus, however, the other teeth are much

835 larger than the isolated Nigersaurus tooth described by Sereno and Wilson (2005). The enamel

836 asymmetry, a diagnostic feature for Nigersaurus, could not be accurately measured on the

837 Moroccan and Algerian tooth sample. To a lesser degree, the labial and lingual wear facet

838 symmetry is seen in both the Brazilian Aptian Tapuisaurus (Zaher et al., 2011), as well as the

839 Late Cretaceous Maxakalisaurus (Kellner et al., 2006; França et al., 2016). However, these teeth

840 show a higher SI than the Moroccan/Algerian sample, as well as stronger labial convexity. The

841 morphology of Morphotype II also does not closely match the conical, peg-shaped teeth of

842 Demandasaurus (Torcida Fernández-Baldor et al., 2011), a rebbachisaurid from the Early

843 Cretaceous of Spain. However, the enamel is relatively smooth on both Morphotype II and

844 Demandasaurus, and moreover, the teeth of Morphotype II are unworn, whereas the

845 Demandasaurus teeth are relatively unworn. 
846 The morphological features on BSPG 1993 IX 2B further show a set of derived titanosaurian

847 characteristics, with a D-shaped cross-section in the middle of the tooth, as seen in

848 Mongolosaurus (Mannion, 2011), but also seen in a titanosauriform tooth from Argentina

849 (García and Cerda, 2010, MPCA-Pv-55, fig. 5). As previously stated, differences in tooth shape

850 can be explained by their relative placement in the toothrow, as seen in Mongolosaurus (having

851 both a cylindrical as well as a D-shaped tooth; Barrett et al., 2002; Mannion, 2011) and

852 Nemegtosaurus (Wilson, 2005). Both Mongolosaurus as well as Nemegtosaurus, however, show

853 a distinct tapering of the apex, which BSPG 1993 IX 2B does not show. Furthermore, differences

854 in shape between upper and lower toothrows is also observed in diplodocoids, such as

855 Diplodocus and Nigersaurus (Sereno \& Wilson, 2005). The labial wear facet in particular is

856 characteristic for diplodocids and dicraeosaurids (Sereno \& Wilson 2005), and while diplodocids

857 are not known from the Cretaceous, rebbachisaurids and dicraeosaurids are (e.g. Sereno \&

858 Wilson, 2005; Gallina et al., 2014). As rebbachisaurids such as Rebbachisaurus garasbae are

859 found in the Kem Kem beds of Morocco (Lavocat, 1954; Mannion \& Barrett, 2013; Wilson \&

860 Allain, 2015), the Aptian-Albian of Niger (Nigersaurus and rebbachisaurids, Sereno et al., 1996;

861 Wilson \& Sereno, 2005; Sereno et al., 2007), and also the Aptian-Albian of Tunisia (Fanti, Cau

$862 \&$ Hassine, 2014; Fanti et al., 2015), and tentatively in the late Barremian-early Aptian of Spain

863 (Pereda Suberbiola et al., 2003; Torcida Fernández-Baldor et al., 2011), they are both

864 biogeographically close, as well as originating from beds near-contemporaneous to those of our

865 tooth sample. Morphotype II therefore is tentatively assigned to Rebbachisauridae indet.

866

867 Quantitative analysis

868 
869 Though quantitative analysis has been applied to theropod teeth in several previous studies (e.g.,

870 Hendrickx \& Mateus, in review; Samman et al., 2005; Fanti \& Therrien, 2007; Ösi, Apesteguía

871 \& Kowalewski, 2010; Hendrickx, Mateus \& Araújo, 2015), a statistical approach to sauropod

872 tooth diversity has thus far only been applied through using one variable - the SI - by Chure et al.

873 (2010), and the number of wear facets on the apex (Averianov \& Sues, 2016). Quantitative

874 analyses on sauropod teeth with two or more variables is therefore an area of study that has not

875 received much attention. Here, we conduct an analysis of sauropod teeth based on multivariate

876 statistical tests. The one-way PERMANOVA revealed significant differences between some of

877 the tested groups $(\mathrm{F}=14.46, \mathrm{p}=0.0001)$. Specific comparisons for each pair of groups are listed in

878 Table 2. Morphotype I shows significant differences in SI and CI ratios with the D-shaped

879 Morphotype from Fox-Amphoux, Patagosaurus, Euhelopus, the Shiramine morphotype, and

880 Maxakalisaurus (Table 2). Differences with some of these groups are congruent with the

881 qualitative approach described above. On the other hand, the SI and CI values of Morphotype I

882 did not significantly differ from those of Atsinganosaurus, Lirainosaurus, Astrodon, the

883 cylindrical Morphotype from Fox-Amphoux, both tooth morphotypes from Lo Hueco, and the

884 titanosaurian teeth from Massecaps, Neuquén, Uzbekistan, and the Bauru Formation, Brazil. (see

885 Table 2). This is in agreement with the qualitative discussion of Morphotype I, where the robust

886 tooth type showed morphological similarities with Astrodon, and the elongated cylindrical type

887 was shown to be morphologically comparable to the Neuquén and Uzbekistan tooth types. It also

888 reinforces the morphological similarities found between Morphotype I with Ibero-Armorican

889 titanosaurs.

890 Concerning Morphotype II, the SI and CI ratios differ significantly from Atsinganosaurus,

891 Patagosaurus, Euhelopus, and Maxakalisaurus (see Table 2) confirming that even though the 
892 wear facets of Morphotype II match those of Maxakalisaurus, there is no further morphological

893 overlap. Unfortunately, the available sample size of Nigersaurus and other rebbachisaurids was

894 not large enough to statistically test their similarities with confidence (see Supplementary Table).

895 However, the very small sample size of this study is not well-suited to this type of approach,

896 therefore the results of this analysis must be taken with caution, and any relationships found

897 between sauropod taxa of our sample must be regarded as tentative. The sauropod relationships

898 suggested by the qualitative and quantitative analysis might not be supported if the sample size is

899 increased. For example, most of the tooth groups of the studied sample were not distinguished

900 after the Bonferroni correction on the post-hoc tests. This might mean that titanosaurian teeth do

901 not possess any clear diagnostic features, or, more likely, that only two variables - the SI and the

902 CI - are not enough to distinguish between titanosaurs, as most taxa and morphotypes strongly

903 group together (see Figure 5). In Figure 5, most teeth from the Moroccan/Algerian samples

904 cluster together, and there is also overlap with other sauropod taxa and/or tooth morphotypes.

905 The teeth with high SI and high CI are Maxakalisaurus, Rapetosaurus, Petrobasaurus and

906 Limaysaurus, whilst teeth with low SI and low CI are Patagosaurus and Jobaria (see Figure 5).

907 The taxon with low SI but high CI is Lapparentosaurus (Figure 5). From the central cluster,

908 Morphotype I and II overlap mostly with the Shiramine teeth, the Uzbekistan teeth, Astrodon,

909 and the Franco-Iberian teeth (i.e. the Lo Hueco, Massecaps, Fox-Amphoux-Métissons and

910 Atsinganosaurus types; Figure 5). Titanosauriform teeth are known to show a large range in

911 morphology, and, moreover, they show some convergence in morphology with more basal

912 sauropod teeth (Garcia \& Cerda 2010). However, it is possible, after the qualitative and

913 quantitative analyses here, that titanosaurian teeth show a similar convergence. Finally, as

914 mentioned previously, the large range of size and shape within one toothrow could also cause 
915 taxa to accrete in Figure 5, though postcranial morphology would cause more morphological

916 scatter. To resolve these issues, a larger sample size, not only of the case study at hand, but also

917 of other (Cretaceous) sauropod teeth, could possibly aid in obtaining a better resolution of future

918 quantitative analyses, however this is beyond the scope of the present study.

919

920

\section{Euro-Gondwanan Cretaceous sauropod diversity and palaeobiogeographical implications}

921

922 To summarize, the described tooth sample from the Albian-Cenomanian Kem Kem beds of

923 Morocco and the Continental Intercalaire of Algeria shows a predominantly non-titanosaurian

924 titanosauriform/titanosaurian assemblage, with only one morphotype (II, with four teeth)

925 showing tentative rebbacchisaurid affinities. When compared with the biogeographically nearest

926 tooth assemblages, namely titanosaurian teeth found in the Ibero-Armorican Island, as well as

927 northwest and central Africa, several probable palaeobiogeographical patterns can be assessed.

928

929 Morphotype I shows morphological affinities with titanosauriforms. Titanosaurian sauropods in

930 the Campanian Kem Kem beds of Morocco have been reported previously (Ibrahim et al., 2016).

931 This titanosaurian predominance is also seen in the later stages of the Cretaceous of Egypt

932 (Lamanna et al., 2017; Sallam et al., 2018), as well as Spain and France (see e.g. Le Loeuff,

933 1995, 2005; Sanz et al., 1999; Garcia et al., 2010; Díaz et al., 2016; Vila, Sellés \& Brusatte,

934 2016). As fourteen teeth from our sample share several similarities with the cylindrical

935 morphotype from Fox-Amphoux-Métisson, with the morphotype A from Lo Hueco and with the

936 D-shaped morphotype from Fox-Amphoux-Métisson, as well as with Atsinganosaurus and the

937 morphotype B from Lo Hueco (Díaz et al., 2012; Díaz, Suberbiola \& Sanz, 2012; Díez Díaz, 
938 Tortosa \& Le Loeuff, 2013; Díez Díaz, Ortega \& Sanz, 2014), this might suggest a possible close

939 affinity between the Cenomanian North African titanosaurian faunas and those from the

940 Campanian-Maastrichtian of southern Europe.

941

942 Morphotype II shows affinities with rebacchisaurids. Rebbachisaurid presence has already been

943 noted from the Early Cretaceous of Niger (Sereno et al., 1999; Sereno \& Wilson, 2005), Tunisia

944 (Fanti et al., 2013, 2015; Fanti, Cau \& Hassine, 2014), and Morocco (Lavocat, 1954, Kellner \&

945 Mader, 1997, Mannion \& Barrett, 2013, Wilson \& Alain, 2015), as well as the United Kingdom

946 (Mannion, Upchurch \& Hutt, 2011) and Spain (Pereda Suberbiola et al., 2003; Torcida

947 Fernández-Baldor et al., 2011). Again, the North African - southern European connection is a

948 tentative explanation for the dispersion of rebbachisaurids between Gondwana and Europe in the

949 Cretaceous (see Figure 6); in addition, rebbachisaurids also seem to be a relatively diverse clade

950 within North and Central Africa during the end of the Aptian-Cenomanian (e.g. Mannion \&

951 Barrett, 2013; Fanti et al., 2014; Wilson and Allain, 2015).

952

953 In previous studies, faunal connections have been demonstrated to exist between North Africa 954 and Italy, such as temporary continental connections during the Barremian (125 Ma, the so-

955 called Apulian route), or more permanent connections caused by carbonate platforms in the peri-

956 Adriatic (Gheerbrant \& Rage, 2006; Canudo et al., 2009; Zarcone et al., 2010; Torcida

957 Fernández-Baldor et al., 2011). These last authors suggested that this route could have allowed

958 for the divergence of the rebbachisaurids Demandasaurus and Nigersaurus. Moreover, Fanti et

959 al., (2016) point to a rebbachisaurid dispersal event leading from Gondwana to a European

960 lineage in the Early Cretaceous. Perhaps the hypothesized continental connection also allowed 
961 titanosaurs to migrate between Laurasia and Gondwana. Furthermore, next to European

962 sauropods, also theropods, crocodyliforms, amphibians, and snakes and even batoids from

963 southern Europe (France, Spain, Italy, Croatia) have been found to show Gondwanan affinities

964 (Soler-Gijón \& López-Martínez, 1998; Gardner, Evans, \& Sigogneau-Russell, 2003; Pereda-

965 Suberbiola et al. 2009, 2015; Sweetman \& Gardner, 2013; Csiki-Sava et al., 2015; Blanco et al., 966 2016, 2017; Dal Sasso et al., 2016; Blanco, in press).

967 The discovery of titanosaurian teeth with similar morphologies from the Cenomanian of Algeria 968 and Morocco, and from the late Campanian-early Maastrichtian of the Ibero-Armorican Island, 969 could indicate that some of these European titanosaurian faunas had a Gondwanan origin.

970 However, this hypothesis needs to be taken with some caution until more postcranial remains

971 (with associated cranial specimens) are found and described from the Early-Late Cretaceous of

972 North Africa and southwestern Europe, as our statistical analysis does not show a high support of 973 any definite grouping between the North African and southern European tooth morphotypes.

974 Csiki-Sava et al. (2015) suggested that European titanosaurs do not seem to have a southern 975 influence, and palaeobiogeographical analyses, as well as this study, show both a Gondwanan 976 (South American) and North American input in European Cretaceous fauna (e.g. Upchurch, 977 2008; Ezcurra \& Agnolín, 2011), which might cautiously be supported by our qualitative and 978 quantitative analyses as well. However, more recent studies have added more information about 979 the North African-southern European connection between these sauropod faunas in the Late 980 Cretaceous (see e.g. Sallam et al., 2018; Díez Díaz et al., 2018). In Figure 6, a tentative 981 palaeobiogeographical construction is shown using the Algerian and Moroccan morphotypes and 982 their morphological counterparts from northwest and central Africa, as well as southern Europe, 983 and possible migratory routes based on previous hypotheses. 


\section{CONCLUSIONS}

986 A sample of eighteen teeth from the Cretaceous Kem Kem beds from Erfoud and Taouz,

987 Morocco, and from the Continental Intercalaire, Algeria, has been studied. The overwhelming

988 majority of this sample shows titanosauriform/titanosaur affinities, with a smaller group showing

989 rebacchisaurid affinities. This is congruent with the results of the statistical analyses. However,

990 the small size of the comparative samples and the relative scarcity of this type of analysis in

991 studies thus far, begs for caution in interpreting results until further study is possible.

992 On the other hand, similarities between tooth samples from northwestern and central Africa, and

993 southwestern Europe, do strongly hint at a possible sauropod faunal exchange through

994 continental connections in the early Late Cretaceous between North and Central Africa, and

995 between North Africa and southwestern Europe. These results support previous hypotheses from

996 earlier studies on faunal exchange and continental connections.

997

998 ACKNOWLEDGEMENTS

999 Oliver Rauhut (BSPG Munich, Germany), Christian Klug and Torsten Scheyer (PIMUZ Zürich,

1000 Switzerland) are profoundly thanked for kindly allowing us to use material from their

1001 collections. We are indebted to Enrico Schwabe (ZSM Munich, Germany) for his kind assistance

1002 in SEM imaging. Many thanks also to Daniela Schwarz and Jens Koch (Museum für Naturkunde

1003 Berlin, Germany) for allowing us to use their Giraffatitan specimen. Jeff Liston kindly checked

1004 the English. The comments and recommendations of editor Kenneth de Baets, and reviewers

1005 Paul Barrett, Attila Ösi, and one anonymous reviewer, greatly improved this manuscript. This

1006 work was part of the BSc thesis of RM at Utrecht University (the Netherlands). 
1009 REFERENCES

1010

1011 Alloul, T., Rage, J.-C., Hamdidouche, R., Jalil, N.-E., 2018. First report on Cretaceous

1012 vertebrates from the Algerian Kem Kem beds. A new procoelous salamander from the

1013 Cenomanian, with remarks on African Caudata. Cretaceous Research 84, 384-388.

1014 Apesteguía S. 2007. The sauropod diversity of the La Amarga Formation (Barremian), Neuquén 1015 (Argentina). Gondwana Research 12:533-546. DOI: 10.1016/j.gr.2007.04.007.

1016 Averianov A, Sues H-D. 2017. Sauropod teeth from the Upper Cretaceous Bissekty Formation of 1017 Uzbekistan. Historical Biology 29:641-653.

1018 Barrett PM, Hasegawa Y, Manabe M, Isaji S, Matsuoka H. 2002. Sauropod dinosaurs from the 1019 Lower Cretaceous of eastern Asia: taxonomic and biogeographical implications. 1020 Palaeontology 45:1197-1217. DOI: 10.1111/1475-4983.00282.

1021 Barrett PM, Pouech J, Mazin J-M, Jones FM. 2016. Teeth of Embryonic or Hatchling Sauropods 1022 from the Berriasian (Early Cretaceous) of Cherves-de-Cognac, France. Acta 1023 Palaeontologica Polonica 61:591-596. DOI: 10.4202/app.00257.2016.

1024 Barrett PM, Wang X-L. 2007. Basal titanosauriform (Dinosauria, Sauropoda) teeth from the 1025 Lower Cretaceous Yixian Formation of Liaoning Province, China. Palaeoworld 16:2651026 271. DOI: 10.1016/j.palwor.2007.07.001.

1027 Belvedere M, Jalil N-E, Breda A, Gattolin G, Bourget H, Khaldoune F, Dyke GJ. 2013.

1028 Vertebrate footprints from the Kem Kem beds (Morocco): A novel ichnological approach 
to faunal reconstruction. Palaeogeography, Palaeoclimatology, Palaeoecology 383-

1030 384:52-58. DOI: 10.1016/j.palaeo.2013.04.026.

1031 Benyoucef M, Läng E, Cavin L, Mebarki K, Adaci M, Bensalah M. 2015. Overabundance of piscivorous dinosaurs (Theropoda: Spinosauridae) in the mid-Cretaceous of North Africa: The Algerian dilemma. Cretaceous Research 55:44-55.

Blanco A. in press. Igdabatis marmii sp. nov. (Myliobatiformes) from the lower Maastrichtian batoid. Journal of Systematic Palaeontology. DOI: 10.1080/14772019.2018.1472673.

Blanco A, Bolet A, Blain HA, Fondevilla V, Marmi J, 2016. Late Cretaceous (Maastrichtian) amphibians and squamates from northeastern Iberia. Cretaceous Research, 57:624-638. DOI:10.1016/j.cretres.2015.07.005.

Blanco A, Szabó M, Blanco À, Marmi J. 2017.Late Cretaceous (Maastrichtian) Chondrichthyes and Osteichthyes from northeastern Iberia. Palaeogeography, Palaeoclimatology, Palaeoecology, 465, 278-294. DOI: 10.1016/j.palaeo.2016.10.039.

1044 (Dinosauria, Sauropoda), a new titanosaur from the Lohan Cura Formation (Aptian, Lower 1045 Cretaceous) of Neuquén, Patagonia, Argentina. Cretaceous Research 27:364-376.

1046 Bonde N. 2012. Danish dinosaurs: a review. Bernissart Dinosaurs and Early Cretaceous 1047 Terrestrial Ecosystems 464:435-451.

1048 Buffetaut E. 1989. Archosaurian reptiles with Gondwanan affinities in the Upper Cretaceous of $1049 \quad$ Europe. Terra nova 1:69-74.

1050 Buffetaut E, Mechin P, Mechin-Salessy A. 1988. Un dinosaure théropode d'affinités 1051 gondwaniennes dans le Crétacé supérieur de Provence. Comptes rendus de l'Académie des 
1052

1053

1054

1055

1056

1057

1058

1059

1060

1061

1062

1063

1064

1065

1066

1067

1068

1069

1070

1071

1072

1073

1074

sciences. Série 2, Mécanique, Physique, Chimie, Sciences de l'univers, Sciences de la Terre 306:153-158.

Calvo JO. 1994. Jaw mechanics in sauropod dinosaurs. Gaia 10:183-193.

Calvo JO, González Riga BJ. 2003. Rinconsaurus caudamirus gen. et sp. nov., a new titanosaurid (Dinosauria, Sauropoda) from the Late Cretaceous of Patagonia, Argentina. Revista geológica de Chile 30:333-353.

Canudo JI, Barco JL, Pereda-Suberbiola X, Ruiz-Omeñaca JI, Salgado L, Fernández-Baldor FT, Gasulla JM. 2009. What Iberian dinosaurs reveal about the bridge said to exist between Gondwana and Laurasia in the Early Cretaceous. Bulletin de la Societe Geologique de France 180:5-11. DOI: 10.2113/gssgfbull.180.1.5.

Carballido JL, Holwerda FM, Pol D, Rauhut OW. 2017. An Early Jurassic sauropod tooth from Patagonia (Cañadon Asfalto Formation: implications for sauropod diversity.. Publicación Electrónica de la Asociación Paleontológica Argentina 17.

Carballido JL, Pol D. 2010. The dentition of Amygdalodon patagonicus (Dinosauria: Sauropoda) and the dental evolution in basal sauropods. Comptes Rendus Palevol 9:83-93.

Carpenter K, Tidwell V. 2005. Reassessment of the Early Cretaceous sauropod Astrodon johnsoni Leidy 1865 (Titanosauriformes). In: Thunder-lizards. Indiana University Press, Bloomington and Indianapolis, 78-114.

Cau A, Maganuco S. 2009. A new theropod dinosaur, represented by a single unusual caudal vertebra, from the Kem Kem Beds (Cretaceous) of Morocco. Atti della Società italiana di scienze naturali e del museo civico di storia naturale di Milano 150:239-257.

Cavin L, Forey PL. 2004. New mawsoniid coelacanth (Sarcopterygii: Actinistia) remains from the Cretaceous of the Kem Kem beds, Southern Morocco. Mesozoic fishes 3:493-506. 
1075 Cavin L, Tong H, Boudad L, Meister C, Piuz A, Tabouelle J, Aarab M, Amiot R, Buffetaut E,

1076 Dyke G, others. 2010. Vertebrate assemblages from the early Late Cretaceous of

1077 southeastern Morocco: an overview. Journal of African Earth Sciences 57:391-412.

1078 Chure D, Britt B, Whitlock J, Wilson J. 2010. First complete sauropod dinosaur skull from the Cretaceous of the Americas and the evolution of sauropod dentition.

1080 Naturwissenschaften 97:379-391. DOI: 10.1007/s00114-010-0650-6.

1081 Chure D., Britt BB., Whitlock JA., Wilson JA. 2010. First complete sauropod dinosaur skull 1082 from the Cretaceous of the Americas and the evolution of sauropod dentition.

$1083 \quad$ Naturwissenschaften 97:379-391.

1084

1085

1086

1087

1088

1089

1090

1091

1092

1093

1094

1095

1096

1097
Csiki-Sava Z, Buffetaut E, Ösi A, Pereda-Suberbiola X, Brusatte SL. 2015. Island life in the Cretaceous - faunal composition, biogeography, evolution, and extinction of land-living vertebrates on the Late Cretaceous European archipelago. ZooKeys 469:1-161. DOI: 10.3897/zookeys.469.8439.

Dal Sasso C, Pierangelini G, Famiani F, Cau A, Nicosia U. 2016. First sauropod bones from Italy offer new insights on the radiation of Titanosauria between Africa and Europe. Cretaceous Research 64:88-109.

Dalla Vecchia FM. 2002. Cretaceous dinosaurs in the Adriatic-Dinaric carbonate platform (Italy and Croatia): paleoenvironmental implications and paleogeographical hypotheses. Memorie della Società Geologica Italiana 57:89-100.

Dalla Vecchia FM, Cau A. 2011. The first record of a notosuchian crocodyliform from Italy. Rivista Italiana di Paleontologia e Stratigrafia (Research In Paleontology and Stratigraphy) 117. 
1098 De Broin F, Grenot C, Vernet R. 1971. Sur la découverte d'un nouveau gisement de Vertébrés

1099 dans le Continental Intercalaire saharien: la Gara Samani (Algérie). Comptes Rendus de $1100 \quad$ l'Académie des Sciences de Paris 272:1219-1221.

1101 D’Emic MD, Mannion PD, Upchurch P, Benson RBJ, Pang Q, Zhengwu C. 2013. Osteology of 1102 Huabeisaurus allocotus (Sauropoda: Titanosauriformes) from the Upper Cretaceous of 1103 China. PLoS ONE 8:e69375. DOI: 10.1371/journal.pone.0069375.

1104 Díez Díaz VD, Garcia G, Knoll F, Suberbiola X., Valentin X. 2012a. New cranial remains of 1105 titanosaurian sauropod dinosaurs from the Late Cretaceous of Fox-Amphoux-Métisson 1106 (Var, SE France). Proceedings of the Geologists’'Association 123:626-637.

1107 Díez Díaz, V., Garcia, G., Pereda Suberbiola, X., Jentgen, B., Stein, K., Godefroit, P. and 1108 Valentin, X. 2018. The ttitanosaurian dinosaur Atsinganosaurus velauciensis 1109 (Sauropoda) from the Upper Cretaceous of southern France: new material, phylogenetic $1110 \quad$ affinities, and palaeobiogeographical implications. Cretaceous Research 91: 429-456.

1111

Díez Díaz VD, Mocho P, Páramo A, Escaso F, Marcos-Fernández F, Sanz JL, Ortega F. 2016. A new titanosaur (Dinosauria, Sauropoda) from the Upper Cretaceous of Lo Hueco

1114 (Cuenca, Spain). Cretaceous Research 68:49-60.

1115 Díez Díaz V, Ortega F, Sanz JL. 2014. Titanosaurian teeth from the Upper Cretaceous of "Lo 1116 Hueco" (Cuenca, Spain). Cretaceous Research:285-291.

1117 Díez Díaz V, Pereda Suberbiola X, Sanz JL. 2012b. Juvenile and adult teeth of the titanosaurian 1118 dinosaur Lirainosaurus (Sauropoda) from the Late Cretaceous of Iberia. Geobios 1119 45:265-274. 
1120 Díez Díaz V, Tortosa T, Le Loeuff J. 2013. Sauropod diversity in the Late Cretaceous of

1121 southwestern Europe: The lessons of odontology. Annales de Paléontologie 99:119-

1122 129. DOI: $10.1016 /$ j.annpal.2012.12.002.

1123 Erickson GM. 1996. Incremental lines of von Ebner in dinosaurs and the assessment of tooth

1124 replacement rates using growth line counts. Proceedings of the National Academy of

$1125 \quad$ Sciences of the United States of America 93:14623-14627.

1126 Ezcurra MD, Agnolín FL. 2011. A New Global Palaeobiogeographical Model for the Late

1127 Mesozoic and Early Tertiary. Systematic Biology.

1128 Fanti F, Cau A, Cantelli L, Hassine M, Auditore M. 2015. New information on Tataouinea

1129 hannibalis from the Early Cretaceous of Tunisia and implications for the tempo and

1130 mode of rebbachisaurid sauropod evolution. PLOS ONE 10:e123475. DOI:

$1131 \quad$ 10.1371/journal.pone.0123475.

1132 Fanti F, Cau A, Hassine M. 2014. Evidence of titanosauriforms and rebbachisaurids (Dinosauria:

1133 Sauropoda) from the Early Cretaceous of Tunisia. Journal of African Earth Sciences

$1134 \quad 90: 1-8$.

1135 Fanti F, Cau A, Hassine M, Contessi M. 2013. A new sauropod dinosaur from the Early

1136 Cretaceous of Tunisia with extreme avian-like pneumatization. Nature Communications

1137 4. DOI: $10.1038 /$ ncomms3080.

1138 Fanti F, Cau A, Panzarin L, Cantelli L. 2016. Evidence of iguanodontian dinosaurs from the

1139 Lower Cretaceous of Tunisia. Cretaceous Research 60:267-274.

1140 Fanti F, Therrien F. 2007. Theropod tooth assemblages from the Late Cretaceous Maevarano

1141 Formation and the possible presence of dromaeosaurids in Madagascar. Acta

$1142 \quad$ Palaeontologica Polonica 52:155. 
1143 Fiorillo AR. 1991. Dental microwear on the teeth of Camarasaurus and Diplodocus:

1144 implications for sauropod paleoecology. In: Fifth Symposium on Mesozoic Terrestrial

1145 Ecosystems and Biota. Contributions from the Palaeontological Museum University of

$1146 \quad$ Oslo, 24.

1147 Fiorillo AR. 1998. Dental micro wear patterns of the sauropod dinosaurs Camarasaurus and

1148 Diplodocus: evidence for resource partitioning in the Late Jurassic of North America.

$1149 \quad$ Historical Biology 13:1-16.

1150 Forey PL, Cavin L. 2007. A new species of Cladocyclus (Teleostei: Ichthyodectiformes) from

1151 the Cenomanian of Morocco. Palaeontologia Electronica 10:1-10.

1152 Forey PL, López-Arbarello A, MacLeod N. 2011. A new species of Lepidotes (Actinopterygii:

1153 Semiontiformes) from the Cenomanian (Upper Cretaceous) of Morocco. Palaeontologia

$1154 \quad$ electronica $14: 1-12$.

1155 França MA, Júlio C de A, Riff D, Hsiou AS, Langer MC. 2016. New lower jaw and teeth

1156 referred to Maxakalisaurus topai (Titanosauria: Aeolosaurini) and their implications for

1157 the phylogeny of titanosaurid sauropods. PeerJ 4:e2054.

1158 Freire PC, Medeiros MA, Lindoso RM. 2007. Sauropod teeth diversity in the Laje do Coringa

1159 fossiliferous site, Eocenomanian of northeastern Brazil. Paleontologia: Cenários de

$1160 \quad$ Vida $1: 523 \mathrm{e} 532$.

1161 Gallina PA, Apesteguía S, Haluza A, Canale JI. 2014. A diplodocid sauropod survivor from the

1162 Early Cretaceous of South America. PLoS ONE 9:e97128. DOI:

1163 10.1371/journal.pone.0097128.

1164 Garcia G, Amico S, Fournier F, Thouand E, Valentin X. 2010. A new titanosaur genus

1165 (Dinosauria, Sauropoda) from the Late Cretaceous of southern France and its 
paleobiogeographic implications. Bulletin de la Société géologique de France 181:269_277.

1168 García Ra, Cerda IA 2010. Dentition and histology in titanosaurian dinosaur embryos from

1169 Upper Cretaceous of Patagonia, Argentina. Palaeontology 53:335-346.

1170 García RA, Cerda IA. 2010. Dentición de titanosaurios (Dinosauria, Sauropoda) del Cretácico

1171 Superior de la provincia de Río Negro, Argentina: morfología, inserción y reemplazo.

1172 Ameghiniana 47:45-60.

1173 Garcia RA, Salgado L. 2012. The Titanosaur Sauropods from the Late Campanian—Early

1174 Maastrichtian Allen Formation of Salitral Moreno, Río Negro, Argentina. Acta

1175 Palaeontologica Polonica 58:269-284.

1176 Gardner JD, Evans SE, Sigogneau-Russell D. 2003. New albanerpetontid amphibians from the

1177 Early Cretaceous of Morocco and Middle Jurassic of England. Acta Palaeontologica

$1178 \quad$ Polonica 48: 301-319.

1179 Gomani EM. 2005. Sauropod dinosaurs from the early Cretaceous of Malawi, Africa.

$1180 \quad$ Palaeontologia Electronica 8:27A.

1181 Hammer Ø, Harper DAT, Ryan PD. 2001. Past: Paleontological Statistics Software Package for

1182 education and data analysis. Palaeontologia Electronica 4:1-9.

1183 Hendrickx C, Mateus O. 2016. Morphofunctional analysis of the quadrate of Spinosauridae

1184 (Dinosauria: Theropoda) and the first definitive evidence of two cohabiting spinosaurids 1185 in the Cenomanian of North Africa. PLoS ONE.

1186 Hendrickx C, Mateus O, Araújo R. 2015. A proposed terminology of theropod teeth (Dinosauria,

1187 Saurischia). Journal of Vertebrate Paleontology 35:e982797. 
1188 Holwerda FM, Pol D, Rauhut OWM. 2015. Using dental enamel wrinkling to define sauropod 1189 tooth morphotypes from the Cañadón Asfalto Formation, Patagonia, Argentina. PLOS 1190 ONE 10:e0118100. DOI: 10.1371/journal.pone.0118100.

1191 Ibrahim N, Dal Sasso C, Maganuco S, Fabbri M, Martill DM, Gorscak E, Lamanna MA. 2016. 1192 Evidence of a derived titanosaurian (Dinosauria, Sauropoda) in the "Kem Kem beds" of

1193 Morocco, with comments on sauropod paleoecology in the Cretaceous of Africa. In:

1194 Cretaceous Period: Biotic Diversity and Biogeography. New Mexico Museum of Natural 1195 History \& Science,

1196 Ibrahim N, Varricchio DJ, Sereno PC, Wilson JA, Dutheil DB, Martill DM, Baidder L, Zouhri S.

1197 2014. Dinosaur footprints and other ichnofauna from the Cretaceous Kem Kem Beds of $1198 \quad$ Morocco. PLoS ONE 9:e90751. DOI: 10.1371/journal.pone.0090751.

1199 Kellner A, Campos D, Azevedo S, Trotta M, Henriques D, Craik M, Silva H. 2006. On a new 1200 titanosaur sauropod from the Bauru Group, Late Cretaceous of Brazil. Boletim do Museu $1201 \quad$ Nacional 74:1-31.

1202 Kellner AW, Mader BJ. 1997. Archosaur teeth from the Cretaceous of Morocco. Journal of $1203 \quad$ Paleontology 71:525-527.

1204 Kues BS, Lehman T, Rigby JK. 1980. The teeth of Alamosaurus sanjuanensis, a Late Cretaceous 1205 sauropod. Journal of Paleontology 54:864-869.

1206 Lamanna MC, Hasegawa Y. 2014. New titanosauriform sauropod dinosaur material from the 1207 Cenomanian of Morocco: implications for paleoecology and sauropod diversity in the 1208 Late Cretaceous of north Africa. Bulletin of Gunma Museum of Natural History 18:1-9. 
1209 Läng E, Boudad L, Maio L, Samankassou E, Tabouelle J, Tong H, Cavin L. 2013. Unbalanced

1210 food web in a Late Cretaceous dinosaur assemblage. Palaeogeography,

1211 Palaeoclimatology, Palaeoecology 381-382:26-32. DOI: 10.1016/j.palaeo.2013.04.011.

1212 Lamanna, M.C., Gorscak, E., Díez Díaz, V., Schwarz, D., El-Dawoudi, I. 2017. Reassessment Of

1213 A Partial Titanosaurian Sauropod Dinosaur Skeleton From The Upper Cretaceous

1214 (Campanian) Quseir Formation Of The Kharga Oasis, Egypt. XV Annual Meeting of the

1215 European Association of Vertebrate Palaeontologists. Zitteliana: 50.

1216 de Lapparent AF, Gorce F. 1960. The dinosaurs of the "Continental Intercalaire" of the central

1217 Sahara. Memoirs of the Geological Society of France XXXIX.

1218 Lavocat R. 1954. Reconnaissance géologique dans les Hammadas des confins algéro-marocains

1219 du Sud. Notes et Mémoires du Service Géologique du Maroc 116:1-147.

1220 Le Loeuff J. 1991. The Campano-Maastrichtian vertebrate faunas from southern Europe and

1221 their relationships with other faunas in the world; palaeobiogeographical implications.

1222 Cretaceous Research 12:93-114. DOI: 10.1016/S0195-6671(05)80019-9.

1223 Le Loeuff J. 1995. Ampelosaurus atacis (nov. gen., nov. sp.), a new titanosaurid (Dinosauria,

1224 Sauropoda) from the Late Cretaceous of the Upper Aude Valley (France). Comptes

1225 Rendus de l'Academie des Sciences-Serie II-Sciences de la Terre et des Planetes

$1226 \quad 321: 693-700$.

1227 Le Loeuff J. 2005. Osteology of Ampelosaurus atacis (Titanosauria) from southern France.

1228 Thunder-Lizards, The Sauropodomorph Dinosaurs:115-137.

1229 Le Loeuff J, Läng E, Cavin L, Buffetaut E. 2012. Between Tendaguru and Bahariya: on the age

1230 of the Early Cretaceous dinosaur sites from the Continental Intercalaire and other African

1231 formations. Journal of Stratigraphy 36:e502. 
1232 Lefranc JP, Guiraud R. 1990. The Continental Intercalaire of northwestern Sahara and its

1233 equivalents in the neighbouring regions. Journal of African Earth Sciences (and the

$1234 \quad$ Middle East) 10:27-77.

1235 Lim J-D, Martin LD, Baek K-S. 2001. The first discovery of a brachiosaurid from the Asian 1236 continent. Naturwissenschaften 88:82-84.

1237 Mahler L. 2005. Record of Abelisauridae (Dinosauria: Theropoda) from the Cenomanian of 1238 Morocco. Journal of Vertebrate Paleontology 25:236-239.

1239 Mannion PD. 2009. A rebbachisaurid sauropod from the Lower Cretaceous of the Isle of Wight, $1240 \quad$ England. Cretaceous Research 30:521-526.

1241 Mannion PD. 2011. A reassessment of Mongolosaurus haplodon Gilmore, 1933, a titanosaurian 1242 sauropod dinosaur from the Early Cretaceous of Inner Mongolia, People’s Republic of 1243 China. Journal of Systematic Palaeontology 9:355-378. DOI:

$1244 \quad 10.1080 / 14772019.2010 .527379$.

1245 Mannion PD, Allain R, Moine O. 2017. The earliest known titanosauriform sauropod dinosaur $1246 \quad$ and the evolution of Brachiosauridae. PeerJ 5:e3217.

1247 Mannion PD, Barrett PM. 2013. Additions to the sauropod dinosaur fauna of the Cenomanian 1248 (early Late Cretaceous) Kem Kem beds of Morocco: Palaeobiogeographical implications 1249 of the mid-Cretaceous African sauropod fossil record. Cretaceous Research 45:49-59. 1250 DOI: $10.1016 /$ j.cretres.2013.07.007.

1251 Mannion PD, Upchurch P, Hutt S. 2011. New rebbachisaurid (Dinosauria: Sauropoda) material 1252 from the Wessex Formation (Barremian, Early Cretaceous), Isle of Wight, United $1253 \quad$ Kingdom. Cretaceous Research 32:774-780. 
1254 Martínez RDF, Lamanna MC, Novas FE, Ridgely RC, Casal GA, Martínez JE, Vita JR, Witmer

1255 LM. 2016. A basal lithostrotian titanosaur (Dinosauria: Sauropoda) with a complete skull:

1256 implications for the evolution and paleobiology of Titanosauria. PLOS ONE

1257 11:e0151661. DOI: 10.1371/journal.pone.0151661.

1258 McGowan AJ, Dyke GJ. 2009. A surfeit of theropods in the Moroccan Late Cretaceous?

1259 Comparing diversity estimates from field data and fossil shops. Geology 37:843-846.

$1260 \quad$ DOI: $10.1130 / G 30188$ A.1.

1261 Meister C, Piuz A, Cavin L, Boudad L, Bacchia F, Ettachfini EM, Benyoucef M. 2017. Late

1262 Cretaceous (Cenomanian-Turonian) ammonites from southern Morocco and south

1263 western Algeria. Arabian Journal of Geosciences 10:1.

1264 Mocho P, Royo-Torres R, Malafaia E, Escaso F, Silva B, Ortega F. 2016. Turiasauria-like teeth

1265 from the Upper Jurassic of the Lusitanian Basin, Portugal. Historical Biology 28:861-

1266 880. DOI: $10.1080 / 08912963.2015 .1049948$.

1267 Novas FE, Dalla Vecchia F, Pais DF. 2005. Theropod pedal unguals from the Late

1268 Cretaceous (Cenomanian) of Morocco, Africa. Revista del Museo Argentino de Ciencias

$1269 \quad$ Naturales 7:167-175.

1270 Ösi A, Csiki-Sava Z, Prondvai E. 2017. A Sauropod Tooth from the Santonian of Hungary and 1271 the European Late Cretaceous 'Sauropod Hiatus.' Scientific reports 7:3261.

1272 Ösi A, Apesteguía S, Kowalewski M. 2010. Non-avian theropod dinosaurs from the early Late 1273 Cretaceous of Central Europe. Cretaceous Research 31:304-320.

1274 Pereda-Suberbiola X., Corral JC., Astibia H., Badiola A., Bardet N., Berreteaga A., Buffetaut E.,

1275 Buscalioni AD., Cappetta H., Cavin L. 2015. Late Cretaceous continental and marine 
1276

1277

1278

1279

1280

1281

1282

1283

1284

1285

1286

1287

1288

1289

1290

1291

1292

1293

1294

1295

1296

1297

1298

vertebrate assemblages of the Laño Quarry (Basque-Cantabrian Region, Iberian Peninsula): an update. Journal of Iberian Geology 41:101.

Pereda Suberbiola X, Torcida F, Izquierdo LA, Huerta P, Montero D, Pérez G. 2003. First rebbachisaurid dinosaur (Sauropoda, Diplodocoidea) from the early Cretaceous of Spain: paleobiogeographical implications. Bulletin de la Societe Geologique de France 174:471479. DOI: $10.2113 / 174.5 .471$.

Pereda-Suberbiola X. 2009. Biogeographical affinities of Late Cretaceous continental tetrapods of Europe: a review. Bulletin de la Société géologique de France 180:57-71.

Poropat SF, Kear BP. 2013. Photographic atlas and three-dimensional reconstruction of the holotype skull of Euhelopus zdanskyi with description of additional cranial elements. PLoS ONE 8:e79932. DOI: 10.1371/journal.pone.0079932.

Rabi M, Sebök N. 2015. A revised Eurogondwana model: Late Cretaceous notosuchian crocodyliforms and other vertebrate taxa suggest the retention of episodic faunal links between Europe and Gondwana during most of the Cretaceous. Gondwana Research 28:1197-1211.

Richter U, Mudroch A, Buckley LG. 2013. Isolated theropod teeth from the Kem Kem Beds (Early Cenomanian) near Taouz, Morocco. Paläontologische Zeitschrift 87:291-309. DOI: $10.1007 / \mathrm{s} 12542-012-0153-1$.

Rodrigues T, Kellner AW, Mader BJ, Russell DA. 2011. New pterosaur specimens from the Kem Kem beds (Upper Cretaceous, Cenomanian) of Morocco. Rivista Italiana di Paleontologia e Stratigrafia (Research In Paleontology and Stratigraphy) 117.

Russell DA. 1996. Isolated dinosaur bones from the Middle Cretaceous of the Tafilalt, Morocco. Bulletin du Muséum National d'Histoire Naturelle 4:349-402. 
1299 Saegusa H, Tomida Y. 2011. Titanosauriform teeth from the Cretaceous of Japan. Anais da 1300 Academia Brasileira de Ciências 83:247-265.

1301 Salgado L, Calvo JO. 1997. Evolution of titanosaurid sauropods. II: the cranial evidence. 1302 Ameghiniana 34:33-48.

1303 Salgado L, Garrido A, Cocca SE, Cocca JR. 2004. Lower Cretaceous rebbachisaurid sauropods 1304 from Cerro Aguada del León (Lohan Cura Formation), Neuquén Province, northwestern 1305 Patagonia, Argentina. Journal of Vertebrate Paleontology 24:903-912.

1306 Sallam HM, Gorscak E, O’Connor PM, El-Dawoudi IA, El-Sayed S, Saber S, Kora MA, Sertich 1307 JJ, Seiffert ER, Lamanna MC. 2018. New Egyptian sauropod reveals Late Cretaceous 1308 dinosaur dispersal between Europe and Africa. Nature Ecology \& Evolution:1.

1309 Samman T, Powell GL, Currie PJ, Hills LV. 2005. Morphometry of the teeth of western North 1310 American tyrannosaurids and its applicability to quantitative classification. Acta 1311 Palaeontologica Polonica 50:757.

1312 Sanz J, Powell J, Le Loeuff J, Martinez R, Pereda Suberbiola X. 1999. Sauropod remains from the Upper Cretaceous of Laño (northcentral Spain). Titanosaur phylogenetic relationships. Estudios del Museo de Ciencias Naturales de Alava 14:235-255.

1315 Sereno PC, Beck AL, Dutheil DB, Larsson HC, Lyon GH, Moussa B, Sadleir RW, Sidor CA, 1316 Varricchio DJ, Wilson GP. 1999. Cretaceous sauropods from the Sahara and the uneven 1317 rate of skeletal evolution among dinosaurs. Science 286:1342-1347.

1318 Sereno PC, Dutheil DB, Iarochene M, Larsson HCE, Lyon GH, Magwene PM, Sidor CA, 1319 Varricchio DJ, Wilson JA. 1996. Predatory Dinosaurs from the Sahara and Late 1320 Cretaceous Faunal Differentiation. Science 272:986-991. DOI:

$1321 \quad$ 10.1126/science.272.5264.986. 
1322 Sereno PC, Wilson JA. 2005. Structure and evolution of a sauropod tooth battery. In: Curry

1323 Rogers K, Wilson JA eds. The Sauropods: Evolution and Paleobiology. Berkeley, CA:

$1324 \quad$ University of California Press, 157-177.

1325 Sereno PC, Wilson JA, Witmer LM, Whitlock JA, Maga A, Ide O, Rowe TA. 2007. Structural

1326 extremes in a Cretaceous dinosaur. PLoS ONE 2:e1230. DOI:

1327 10.1371/journal.pone.0001230.

1328 Soler-Gijón R, López-Martínez N. 1998. Sharks and rays (chondrichthyes) from the

1329 Upper Cretaceous red beds of the south-central Pyrenees (Lleida, Spain): indices of

1330 an India-Eurasia connection. Palaeogeogr. Palaeoclimatol. Palaeoecol. 141, 1-12.

1331 Sweetman SC, Gardner JD. 2013. A new albanerpetontid amphibian from the Barremian (Early

1332 Cretaceous) Wessex Formation of the Isle of Wight, southern England. Acta

1333 Palaeontologica Polonica 58 (2): 295-324.

1334 Torcida Fernández-Baldor FT, Canudo JI, Huerta P, Moreno-Azanza M, Montero D. 2017.

1335 Europatitan eastwoodi, a new sauropod from the lower Cretaceous of Iberia in the initial

1336 radiation of somphospondylans in Laurasia. PeerJ 5:e3409.

1337 Torcida Fernández-Baldor F, Canudo JI, Huerta P, Montero D, Pereda Suberbiola X. 2011.

1338 Demandasaurus darwini, a new rebbachisaurid sauropod from the Early Cretaceous of

1339 the Iberian Peninsula. Acta Palaeontologica Polonica 56:535-552. DOI:

$1340 \quad$ 10.4202/app.2010.0003.

1341 Upchurch P. 1995. The evolutionary history of sauropod dinosaurs. Philosophical Transactions

1342 of the Royal Society of London. Series B: Biological Sciences 349:365-390.

1343 Upchurch P. 1998. The phylogenetic relationships of sauropod dinosaurs. Zoological Journal of 1344 the Linnean Society 124:43-103. 
1345 Upchurch P. 2008. Gondwanan break-up: legacies of a lost world? Trends in ecology \& 1346 evolution 23:229-236.

1347 Upchurch P, Barrett PM. 2000. The evolution of sauropod feeding mechanisms. In: Sues H-D ed. $1348 \quad$ Evolution of herbivory in terrestrial vertebrates: perspectives from the fossil record. 1349 Cambridge: Cambridge University Press, 79-122.

1350 Upchurch P, Barrett PM, Dodson P. 2004. Sauropoda. In: Weishampel DB, Dodson P, Osmólska 1351 H eds. The Dinosauria. Second edition. Berkeley, CA: University of California Press, $1352 \quad 259-322$.

1353 Vila B, Sellés AG, Brusatte SL. 2016. Diversity and faunal changes in the latest Cretaceous 1354 dinosaur communities of southwestern Europe. Cretaceous Research 57:552-564. DOI: $1355 \quad 10.1016 / j . c r e t r e s .2015 .07 .003$.

1356 Vullo R, Néraudeau D, Allain R, Cappetta H. 2005. Un nouveau gisement à microrestes de 1357 vertébrés continentaux et littoraux dans le Cénomanien inférieur de Fouras (Charente1358 Maritime, Sud-Ouest de la France). Comptes Rendus Palevol 4:95-107.

1359 Vullo R, Neraudeau D, Lenglet T. 2007. Dinosaur teeth from the Cenomanian of Charentes, 1360 western France: evidence for a mixed Laurasian-Gondwanan assemblage. Journal of $1361 \quad$ Vertebrate Paleontology 27:931-943.

1362 Wellnhofer P, Buffetaut E. 1999. Pterosaur remains from the Cretaceous of Morocco. $1363 \quad$ Paläontologische Zeitschrift 73:133.

1364 Wiersma K, Sander PM. 2016. The dentition of a well-preserved specimen of Camarasaurus sp.: 1365 implications for function, tooth replacement, soft part reconstruction, and food intake. 1366 PalZ:1-17. DOI: 10.1007/s12542-016-0332-6. 
1367 Wilson JA. 2002. Sauropod dinosaur phylogeny: critique and cladistic analysis. Zoological $1368 \quad$ Journal of the Linnean Society 136:215-275.

1369 Wilson JA. 2005. Redescription of the Mongolian sauropod Nemegtosaurus mongoliensis

1370 Nowinski (Dinosauria: Saurischia) and comments on Late Cretaceous sauropod diversity. $1371 \quad$ Journal of Systematic Palaeontology 3:283-318.

1372 Wilson JA, Allain R. 2015. Osteology of Rebbachisaurus garasbae Lavocat, 1954, a diplodocoid 1373 (Dinosauria, Sauropoda) from the early Late Cretaceous-aged Kem Kem beds of southeastern Morocco. Journal of Vertebrate Paleontology 35:e1000701.

1375 Wilson JA, Sereno PC. 1998. Early evolution and higher-level phylogeny of sauropod dinosaurs. Journal of Vertebrate Paleontology 18:1-79. Zaher H, Pol D, Carvalho AB, Nascimento PM, Riccomini C, Larson P, Juarez-Valieri R, Pires-Domingues R, da Silva NJ, de Almeida CD. 2011. A complete skull of an Early Cretaceous sauropod and the evolution of advanced titanosaurians. PLOS ONE 6:e16663.

Zarcone G, Petti FM, Cillari A, Di Stefano P, Guzzetta D, Nicosia U. 2010. A possible bridge between Adria and Africa: new palaeobiogeographic and stratigraphic constraints on the Mesozoic palaeogeography of the Central Mediterranean area. Earth-Science Reviews 103:154-162.

1384

Figure and Table legends

1386

1387 Figure 1: Geological setting of Kem Kem beds, Morocco, and continental intercalaire, Algeria.

1388 Taouz and Erfoud are indicated. The localities of Lo Hueco, Spain, and Fox-Amphoux-

1389 Métissons and Massecaps are also portrayed. 
1390 A: stratigraphical column of Kem Kem beds (after Ibrahim et al., 2014). B: stratigraphical

1391 column of continental intercalaire, Algeria, (after Forey and Cavin, 2010).

1392

1393 Figure 2: Images of BSPG 1993 IX 331A (A), BSPG 1993 IX 331B (B), BSPG 1993 IX 331C

1394 (C), BSPG 1993 IX 313A (D), BSPG 1993 IX 2A (E), BSPG 1993 IX 2B (F), BSPG 1993 IX 2C

1395 (G), and BSPG 1993 IX 2D (H).

1396 In basal view, apical view, labial view, lingual view, distal view, and mesial view. The scale bar

1397 equals $1 \mathrm{~cm}$.

1398

1399 Figure 3: Images of PIMUZ A/III 0823a (A), PIMUZ A/III 0823b (B) PIMUZ A/III 0823c (C),

1400 PIMUZ A/III 0823d (D), PIMUZ A/III 0823e (E), PIMUZ A/III 0823f (F), PIMUZ A/III

1401 0823g(G), PIMUZ A/III 0823h (H), PIMUZ A/III 0823i (I), PIMUZ A/III 0823j (J).

1402 In apical view, basal view, labial view, lingual view, distal view, and mesial view. The scale bar 1403 equals $1 \mathrm{~cm}$.

1404

1405 Figure 4: SEM pictures of enamel wrinkling. BSPG 1993 IX 331A in labial (A) and lingual (B)

1406 view, BSPG 1993 IX 331B in labial (C) and lingual (D) view, BSPG 1993 IX 313A in labial (E)

1407 and lingual (F) view, BSPG 1993 IX 2A in labial (G) and lingual (H) view, BSPG 1993 IX 2B in

1408 labial (I) and lingual (J) view, and BSPG 1993 IX 2D in labial (K) and lingual (L) view. The

1409 scale bar equals $500 \mu \mathrm{m}$.

1410

1411 Figure 5: Dispersion plot of Cretaceous tooth morphotypes, with Jurassic outgroups. See

1412 coloured boxes in legend for sauropod groups. 
1414 Figure 6: Palaeobiogeographical reconstruction of northwest Africa and southern Europe during

1415 the Cenomanian (black line) and Campanian-Maastrichtian (grey line), with possible migration

1416 routes (dotted green line). Adapted from Csiki-Sava et al., (2015).

1417 Tooth morphotype I next to tooth morphotypes A and B from Lo Hueco (from Díez Díaz, Ortega

1418 \& Sanz, 2014) Fox-Amphoux-Métissons cylindrical type and D-shaped morphotype (from Díez

1419 et al., 2012), the Massecaps titanosaur and Atsinganosaurus (from Díez Díaz, Tortosa \& Le

1420 Loeuff, 2013). Tooth morphotype II next to Nigersaurus (from Sereno et al., 2007), and

1421 Demandasaurus (From Torcida Fernández-Baldor et al., 2011).

1422

1423 Table 1: Measurements, wear stage (after Saegusa \& Tomida, 2011) and enamel morphology of 1424 each tooth. Measurements in $\mathrm{mm}$.

1425

1426 Table 2: One-way PERMANOVA comparisons for each pair of sauropod groups.

1427

1428 Supplementary Table 1: All tooth samples for the quantitative analysis with SI and CI from pers. 1429 obs. or literature.

1430

1431 
Figure 1

Geological setting of Kem Kem beds, Morocco, and Continental Intercalaire, Algeria.

Taouz and Erfoud are indicated. localities of Lo Hueco, Spain, and France (FAM, AIX, Massecaps) are also portrayed. A: Map of Europe and Africa. B: Close-up of North Africa and Southern Europe. C: stratigraphical column of Kem Kem beds (after Belvedere et al., 2013; Ibrahim et al., 2014). D: stratigraphical column of Continental Intercalaire, Algeria, (after Forey, López-Arbarello \& MacLeod, 2011).

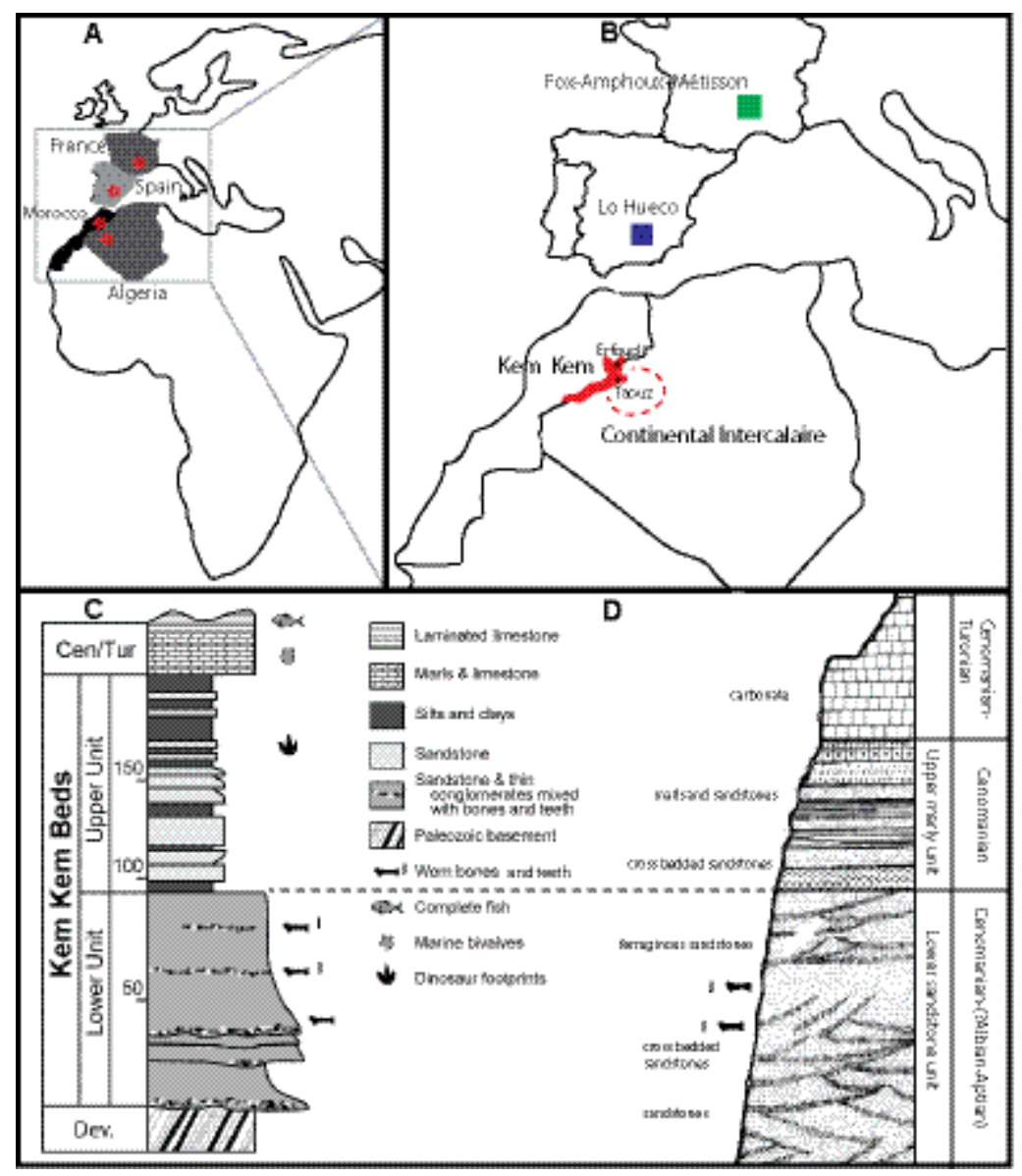


Figure 2

Images of BSPG 1993 IX 331A (A), BSPG 1993 IX 331B (B), BSPG 1993 IX 331C (C), BSPG 1993 IX 313A (D), BSPG 1993 IX 2A (E), BSPG 1993 IX 2B (F), BSPG 1993 IX 2C (G), and BSPG 1993 IX 2D (H).

In basal view, apical view, labial view, lingual view, distal view, and mesial view. The scale bar equals $1 \mathrm{~cm}$. Images taken by RM. 

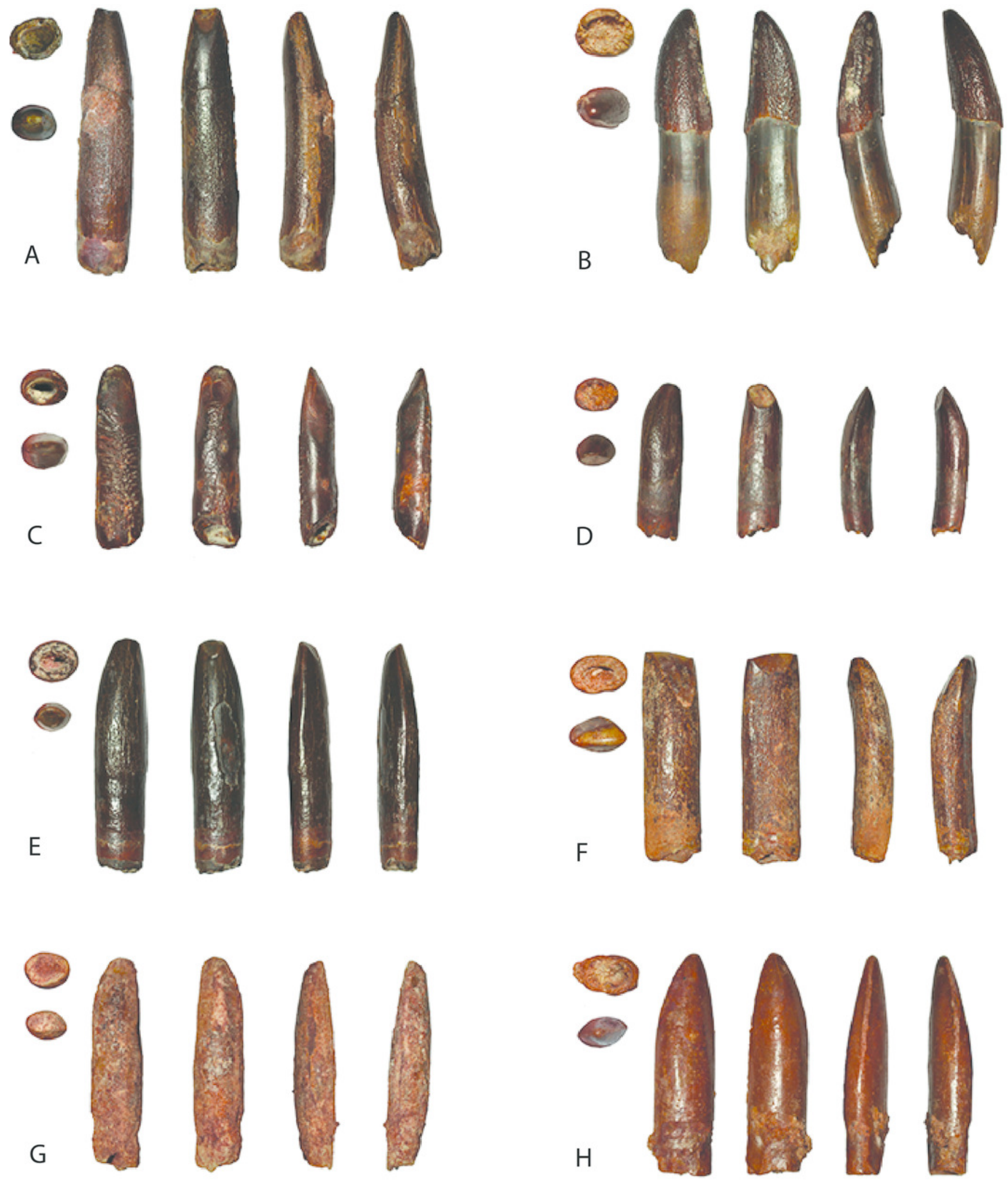

$1 \mathrm{~cm}$ 


\section{Figure 3}

Images of PIMUZ A/III 0823a (A), PIMUZ A/III 0823b (B) PIMUZ A/III 0823c (C), PIMUZ A/III 0823d (D), PIMUZ A/III 0823e (E), PIMUZ A/III 0823f (F), PIMUZ A/III 0823g(G), PIMUZ A/III 0823h (H), PIMUZ A/III 0823i (I), PIMUZ A/III 0823j (J).

In apical view, basal view, labial view, lingual view, distal view, and mesial view. The scale bar equals $1 \mathrm{~cm}$. Images taken by $\mathrm{FH}$. 


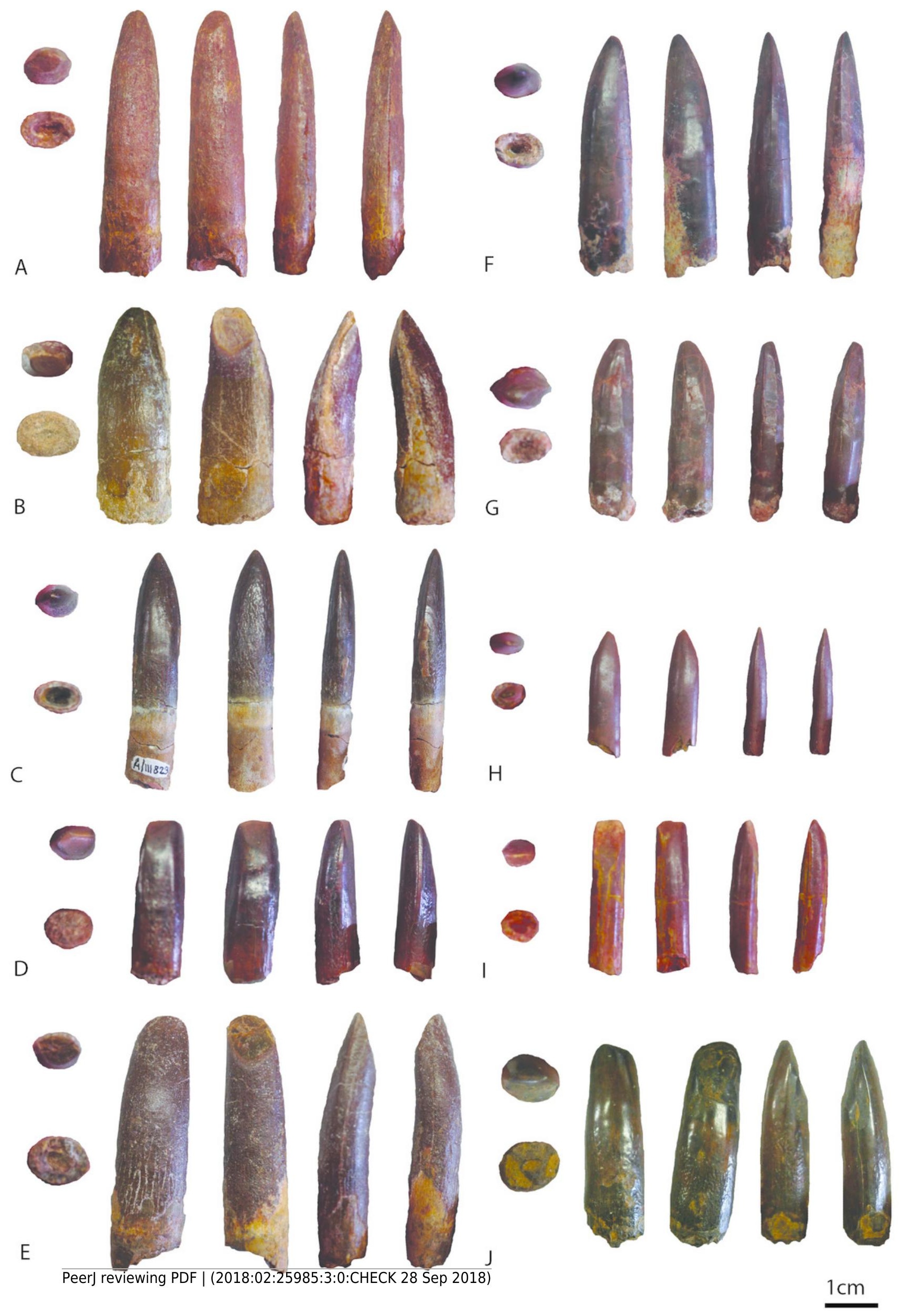




\section{Figure 4}

SEM pictures of enamel wrinkling.

BSPG 1993 IX 331A in labial (A) and lingual (B) view, BSPG 1993 IX 331B in labial (C) and lingual (D) view, BSPG 1993 IX 313A in labial (E) and lingual (F) view, BSPG 1993 IX 2A in labial (G) and lingual (H) view, BSPG 1993 IX 2B in labial (I) and lingual (J) view, and BSPG 1993 IX 2D in labial (K) and lingual (L) view. The scale bar equals 500 $\mathrm{mm}$. Images taken by FH and $R M$. 


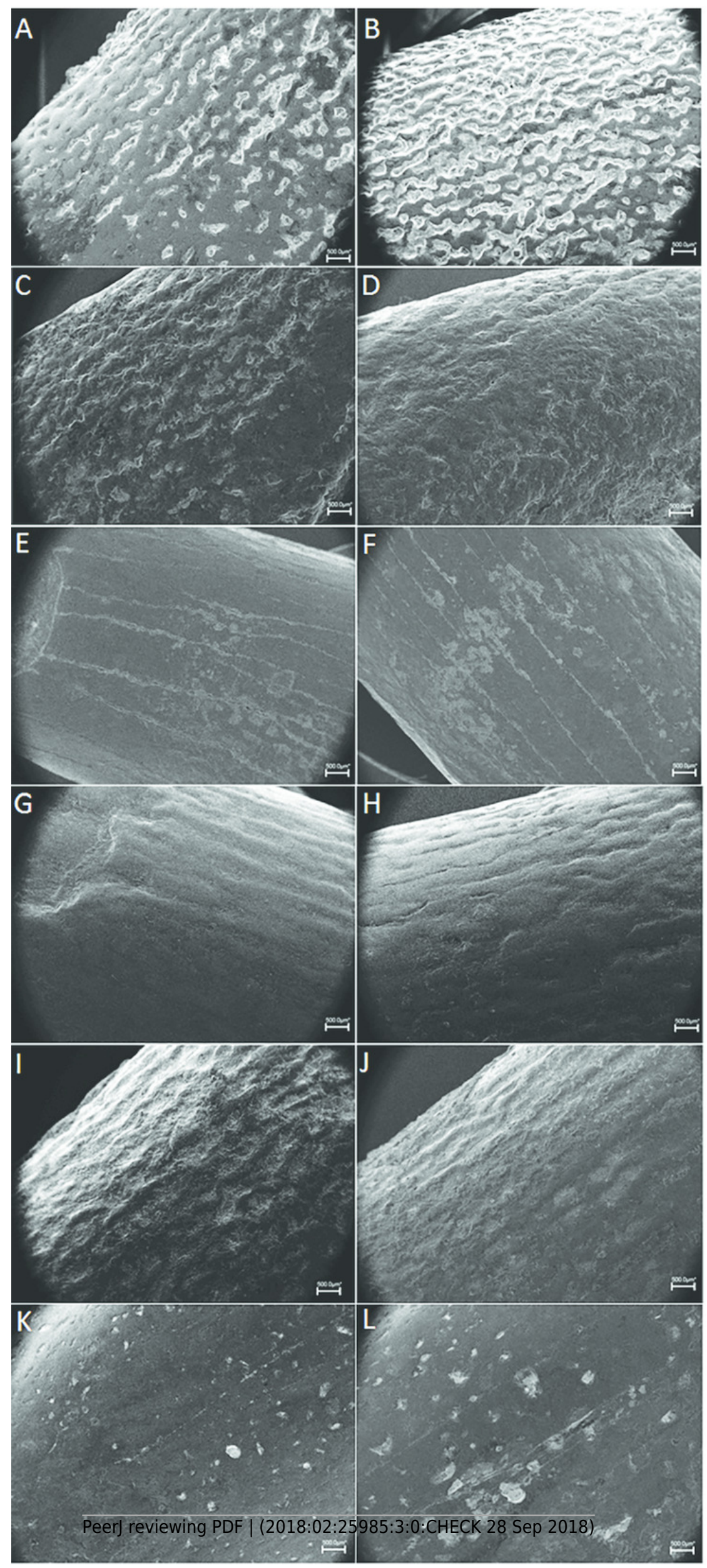


Figure 5

Dispersion plot of Cretaceous sauropod tooth morphotypes, with Jurassic outgroups.

See coloured boxes in legend for sauropod groups. A: All groups highlighted. B: Morphotype I and II highlighted. 


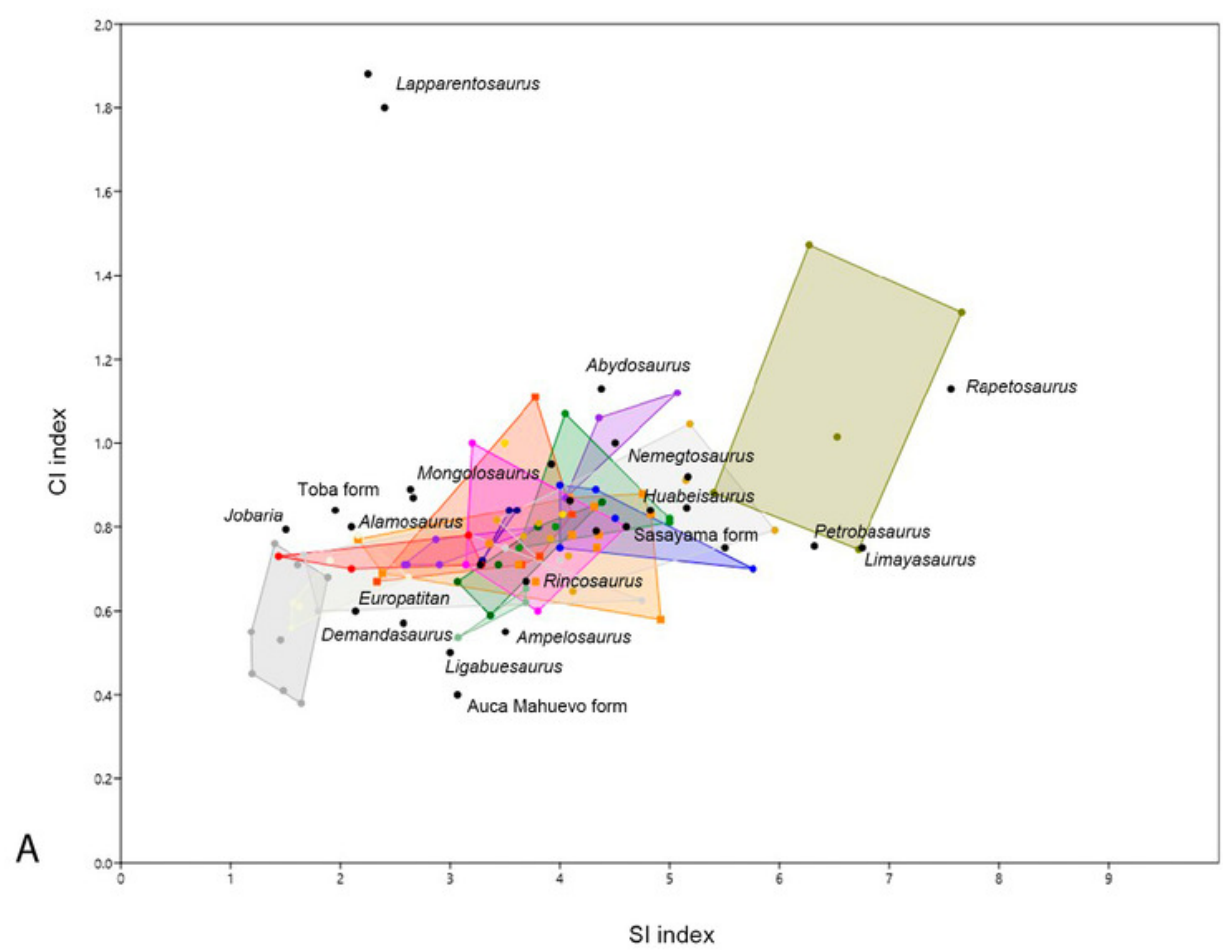

Morphotype I

Morphotype II

Atsinganosaurus

Fox-Amphoux-Métisson C

Fox-Amphoux-Métisson D

Lirainosaurus

Lo Hueco Morphotype A

Lo Hueco Morphotype B

Massecaps titanosaur

Patagosaurus

Euhelopus

Shiramine form

Astrodon

Neuquen form

Uzbekistan form

Maxakalisaurus

Bauru form

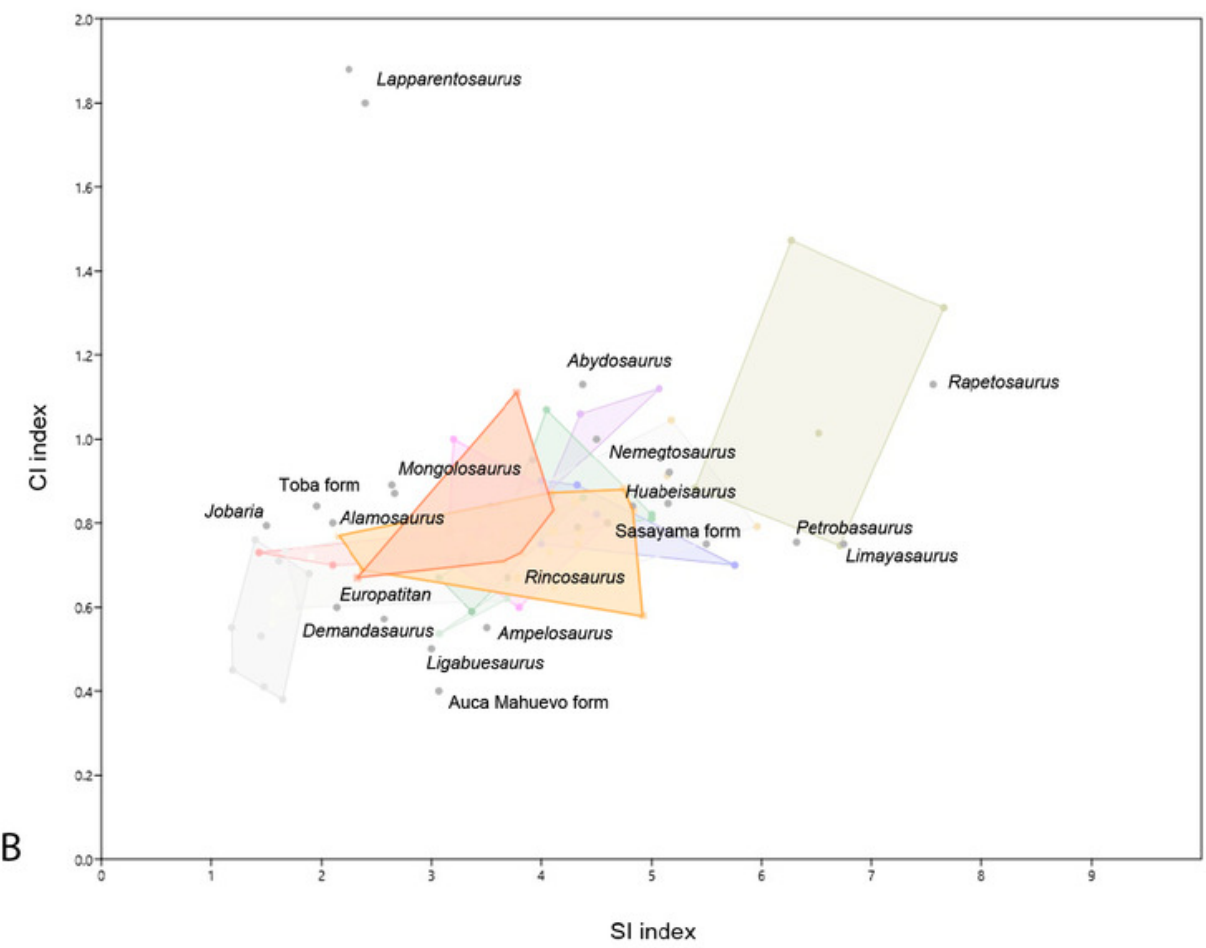

Morphotype I

Morphotype II

Atsinganosaurus *

Fox-Amphoux-Métisson C *

Fox-Amphoux-Métisson D *

Lirainosaurus *

Lo Hueco Morphotype A *

Lo Hueco Morphotype B *

Massecaps titanosaur *

Patagosaurus

Euhelopus

Shiramine form

Astrodon

Neuquen form

Uzbekistan form

Maxakalisaurus

Bauru form

* Titanosauriformes 
Figure 6

Palaeobiogeographical reconstruction of northwest Africa and southern Europe using sauropod tooth morphotypes.

A: northwest Africa and southern Europe during the Cenomanian (black line) and CampanianMaastrichtian (grey line), with possible migration routes (dotted green line), adapted from Csiki-Sava et al., (2015). B: Tooth morphotype I next to tooth morphotypes A and B from Lo Hueco (from Díez Díaz, Ortega \& Sanz, 2014) Fox-Amphoux-Métissons cylindrical type and Dshaped morphotype (from Díez et al., 2012), the Massecaps titanosaur and Atsinganosaurus (from Díez Díaz, Tortosa \& Le Loeuff, 2013). C: Tooth morphotype II next to Nigersaurus (from Sereno et al., 2007), and Demandasaurus (From Torcida Fernández-Baldor et al., 2011).

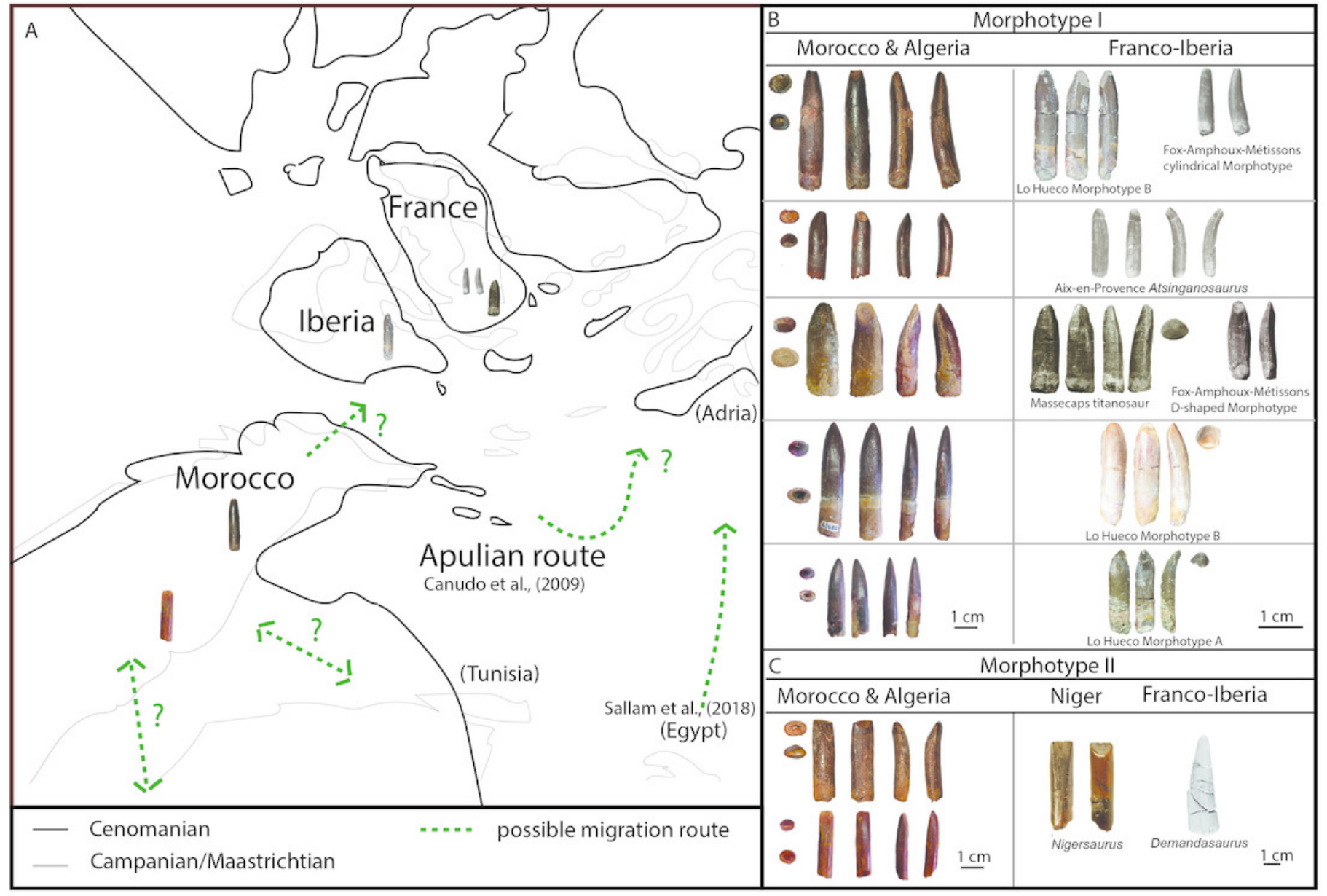




\section{Table $\mathbf{1}$ (on next page)}

Measurements, wear stage (after Saegusa \& Tomida, 2011) and enamel morphology of each tooth.

Measurements in $\mathrm{mm}$. 


\begin{tabular}{|c|c|c|c|c|c|c|c|c|c|c|c|c|c|c|c|}
\hline $\begin{array}{l}\text { Specimen } \\
\mathrm{nr}\end{array}$ & $\begin{array}{l}\text { Apico- } \\
\text { basal } \\
\text { length }\end{array}$ & $\begin{array}{l}\text { Abrasion } \\
\text { stage }\end{array}$ & $\begin{array}{l}\text { Mesio- } \\
\text { distal } \\
\text { base }\end{array}$ & $\begin{array}{l}\text { Mesio- } \\
\text { distal } \\
\text { middle }\end{array}$ & $\begin{array}{l}\text { Mesio- } \\
\text { distal } \\
\text { apex }\end{array}$ & $\begin{array}{l}\text { Labio- } \\
\text { lingual } \\
\text { base }\end{array}$ & $\begin{array}{l}\text { Labio- } \\
\text { lingual } \\
\text { middle }\end{array}$ & $\begin{array}{l}\text { Labio- } \\
\text { lingual } \\
\text { apex }\end{array}$ & SI & $\mathrm{Cl}$ & $\begin{array}{l}\text { Abrasion } \\
\text { stage }\end{array}$ & $\begin{array}{l}\text { Number } \\
\text { and location } \\
\text { of } \\
\text { wear } \\
\text { facets }\end{array}$ & $\begin{array}{l}\text { Hypothetical } \\
\text { placement } \\
\text { in the snout }\end{array}$ & $\begin{array}{l}\text { Apical } \\
\text { third } \\
\text { cross- } \\
\text { section }\end{array}$ & $\begin{array}{l}\text { Enamel } \\
\text { ornamentation }\end{array}$ \\
\hline BSPG 1993 IX 331A & 60 & 53 & 12 & 12,3 & 6,2 & 10 & 10,5 & 4 & 4,3089 & 0,8536 & $\mathrm{~F} 2$ & $2(a p, \ln )$ & Premaxilla & Elliptical & Anastomosed \\
\hline BSPG 1993 IX 331B & 48 & 24 & 10,8 & 11,1 & 4,5 & 8,5 & 8,5 & 3 & 2,1621 & 0,7657 & F1 & 0 & - & Elliptical & Anastomosed \\
\hline BSPG 1993 IX 331C & 37 & 37 & 10 & 9 & 5,5 & 7,5 & 7,5 & 2 & 4,1111 & 0,8333 & F4-F5 & $4(\mathrm{Ib}, \mathrm{In}, \mathrm{m}, \mathrm{d})$ & Maxilla & Elliptical & $\begin{array}{l}\text { (worn) } \\
\text { scratches and } \\
\text { apical pits }\end{array}$ \\
\hline BSPG 1993 IX 313A & 27,5 & 27,5 & 8,2 & 8,2 & 4,5 & 6 & 6,2 & 1 & 3,3536 & 0,7560 & F2 & $1(\ln )$ & Premaxilla & Elliptical & $\begin{array}{l}\text { Longitudinal ridges } \\
\text { (but worn) }\end{array}$ \\
\hline BSPG 1993 IX 2A & 51 & 50 & 10,5 & 11,5 & 5,5 & 8,5 & 9 & 2 & 4,3478 & 0,7826 & $\mathrm{~F} 2$ & $1(\ln )$ & Maxilla & $\begin{array}{l}\text { Lemon } \\
\text { shaped }\end{array}$ & $\begin{array}{l}\text { Longitudinal ridges } \\
\text { (but worn) }\end{array}$ \\
\hline BSPG 1993 IX 2B & 47,5 & 47,5 & 13 & 13 & 11,5 & 9 & 9,2 & 3 & 3,6538 & 0,7076 & F2-F3 & $2(\mathrm{lb}, \ln )$ & $\begin{array}{l}\text { Anterior } \\
\text { dentary }\end{array}$ & $\begin{array}{l}\text { Lemon } \\
\text { shaped }\end{array}$ & Longitudinal ridges \\
\hline BSPG 1993 IX 2C & 47 & 47 & 10 & 11,5 & 5 & 8 & 10 & 2 & 4,0869 & 0,8695 & F2 & $1(\mathrm{lb})$ & $\begin{array}{l}\text { Anterior } \\
\text { dentary }\end{array}$ & $\begin{array}{l}\text { Lemon } \\
\text { shaped }\end{array}$ & $\begin{array}{l}\text { No } \\
\text { (because of } \\
\text { preservation) }\end{array}$ \\
\hline BSPG 1993 IX 2D & 38 & 38 & 9,5 & 10,5 & 1,5 & 6,5 & 7,5 & 1,5 & 3,6190 & 0,7142 & F1 & 0 & Anterior (?) & $\begin{array}{l}\text { Lemon } \\
\text { shaped }\end{array}$ & $\begin{array}{l}\text { (worn) } \\
\text { w/pits and scratches }\end{array}$ \\
\hline PIMUZ A/III 0823 a & 66 & 59 & 15 & 12 & 7 & 8 & 7 & 4 & 4,9166 & 0,5833 & F2 & $1(\ln )$ & Premaxilla & Elliptical & $\begin{array}{l}\text { Anastomosed } \\
\text { (but worn) }\end{array}$ \\
\hline PIMUZ A/III 0823 b & 39 & 31 & 14,5 & 13 & 7 & 8 & 9 & 7 & 2,3846 & 0,6923 & F2 & $1(\ln )$ & Premaxilla & D-shaped & Anastomosed \\
\hline PIMUZ A/III 0823 c & 57 & 34 & 11 & 9 & 5 & 6 & 6 & 3 & 3,7777 & 0,6666 & F1 & 0 & - & $\begin{array}{l}\text { Lemon } \\
\text { shaped }\end{array}$ & $\begin{array}{l}\text { Anastomosed } \\
\text { w/protrusions }\end{array}$ \\
\hline PIMUZ A/III $0823 \mathrm{~d}$ & 24 & 21 & 7 & 9 & 6 & 6 & 6 & 4 & 2,3333 & 0,6666 & $F 2-F 3$ & $2(\mathrm{Ib}, \ln )$ & Anterior & $\begin{array}{l}\text { Elliptical } \\
\text { (worn) }\end{array}$ & $\begin{array}{l}\text { Anastomosed } \\
\text { w/protrusions }\end{array}$ \\
\hline PIMUZ A/III 0823 e & 43 & 37 & 10 & 9 & 8 & 9 & 7 & 4 & 4,1111 & 0,7777 & F2 & $2(\mathrm{lb}, \ln )$ & Premaxilla & $\begin{array}{l}\text { Lemon } \\
\text { shaped }\end{array}$ & $\begin{array}{l}\text { Reticulate } \\
\text { w/ protrusions }\end{array}$ \\
\hline PIMUZ A/III 0823 f & 42 & 38 & 9 & 8 & 4 & 6 & 7 & 3 & 4,75 & 0,875 & F1 & 0 & - & Elliptical & Smooth \\
\hline PIMUZ A/III $0823 \mathrm{~g}$ & 31 & 29 & 7 & 6 & 3 & 6 & 5 & 3 & 4,8333 & 0,8333 & F4 & $3(\ln , m, d)$ & Maxilla & $\begin{array}{l}\text { Lemon } \\
\text { shaped } \\
\text { (faint) }\end{array}$ & $\begin{array}{l}\text { Smooth } \\
\text { (w/ apicobasal } \\
\text { striations) }\end{array}$ \\
\hline PIMUZ A/III $0823 \mathrm{~h}$ & 26 & 26 & 5 & 6 & 5 & 4 & 4,5 & 3 & 4,3333 & 0,75 & F1-F2 & 1 (ap) & - & Elliptical & Smooth \\
\hline PIMUZ A/III 0823 i & 21 & 21 & 5 & 5,5 & 3 & 3 & 4 & 2 & 3,8181 & 0,7272 & $F 2-F 3$ & $2(\mathrm{Ib}, \ln )$ & $\begin{array}{l}\text { Anterior } \\
\text { dentary }\end{array}$ & $\begin{array}{l}\text { Lemon } \\
\text { shaped }\end{array}$ & Smooth \\
\hline PIMUZ A/III 0823 j & 34 & 34 & 11 & 9 & 8 & 9 & 10 & 4 & 3,7777 & 1,1111 & F4 & $3(\ln , \mathrm{m}, \mathrm{d})$ & Maxilla & $\begin{array}{l}\text { Elliptical } \\
\text { (worn) }\end{array}$ & Chevron-like \\
\hline
\end{tabular}




\section{Table 2 (on next page)}

One-way PERMANOVA comparisons for each pair of sauropod groups.

*non-neosauropod eusauropod; **non-titanosaurian titanosaurifom; ***titanosaur; ?unknown or resolved in this study 


\begin{tabular}{|c|c|c|c|c|c|c|c|c|c|c|c|c|c|c|c|c|c|}
\hline & $\begin{array}{l}\text {-' } \\
\frac{0}{2} \\
\frac{2}{2}\end{array}$ & $\begin{array}{l}=1 \\
\text { s' } \\
\frac{1}{0} \\
\sum\end{array}$ & 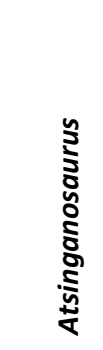 & 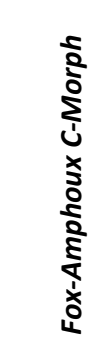 & 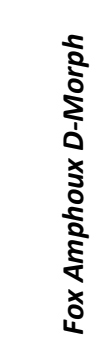 & 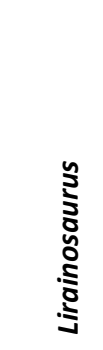 & 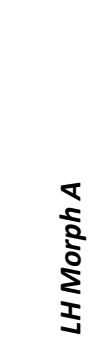 & $\begin{array}{l}\infty \\
\frac{1}{2} \\
\sum^{\frac{1}{2}} \\
\text { I }\end{array}$ & 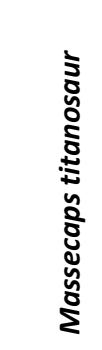 & 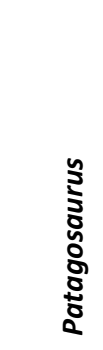 & $\begin{array}{l}\frac{y}{3} \\
\frac{0}{0} \\
\frac{5}{5}\end{array}$ & 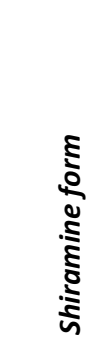 & 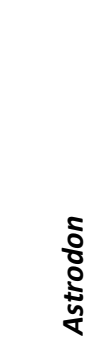 & 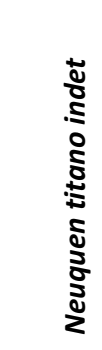 & 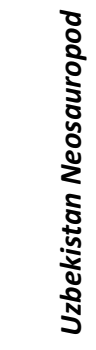 & 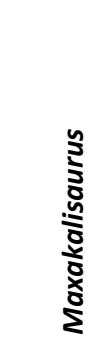 & 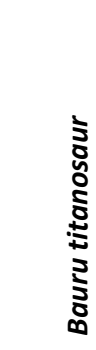 \\
\hline & & 0,397 & 0,191 & 0,258 & 0,038 & & 0,472 & 0,355 & 0,412 & 0,000 & 0,000 & 0,009 & 0,640 & 0,077 & 0,262 & 0,000 & 0,415 \\
\hline Morph_l? & & 5 & 7 & 4 & 3 & 0,751 & 9 & 6 & 7 & 1 & 2 & 6 & 8 & 4 & 3 & 6 & 2 \\
\hline & & & 0,022 & 0,075 & 0,180 & 0,862 & 0,875 & 0,115 & & 0,000 & 0,003 & 0,113 & 0,856 & 0,370 & 0,090 & 0,008 & \\
\hline Morph_II? & & & 8 & 2 & 9 & 3 & 8 & 6 & 1 & 8 & 8 & 1 & 8 & 2 & 9 & 7 & 0,763 \\
\hline & & & & 0,838 & 0,008 & 0,388 & 0,042 & 0,697 & 0,034 & 0,000 & 0,002 & 0,009 & 0,139 & 0,049 & 0,686 & 0,016 & 0,035 \\
\hline Atsinganosaurus $^{* * *}$ & & & & 3 & 3 & 8 & 7 & 1 & 7 & 6 & 2 & 3 & 9 & 5 & 4 & 5 & 7 \\
\hline FoxAmphoux C- & & & & & 0,017 & 0,189 & 0,053 & 0,645 & 0,095 & 0,005 & 0,012 & 0,026 & 0,142 & & 0,600 & 0,017 & 0,102 \\
\hline$M^{M r p h} h^{* * *}$ & & & & & 2 & 2 & 2 & 8 & 4 & 4 & 2 & 8 & 3 & 0,106 & 5 & 6 & 8 \\
\hline FoxAmphoux D- & & & & & & 0,147 & 0,079 & 0,014 & & 0,000 & 0,007 & 0,358 & 0,111 & 0,985 & 0,005 & 0,008 & 0,154 \\
\hline Morph $^{* * *}$ & & & & & & 4 & 2 & 3 & 0,144 & 9 & 4 & 1 & 2 & 5 & 7 & 2 & 5 \\
\hline & & & & & & & 0,666 & 0,236 & 0,503 & 0,022 & 0,037 & 0,136 & 0,933 & 0,436 & & & 0,598 \\
\hline Lirainosaurus ${ }^{* * *}$ & & & & & & & 2 & 2 & 2 & 4 & 4 & 4 & 8 & 3 & 0,374 & 0,05 & 9 \\
\hline & & & & & & & & 0,093 & 0,711 & 0,001 & 0,001 & 0,036 & 0,908 & & 0,091 & 0,007 & 0,660 \\
\hline LoHueco Morph $A^{* * *}$ & & & & & & & & 2 & 9 & 5 & 9 & 6 & 1 & 0,321 & 3 & 9 & 7 \\
\hline & & & & & & & & & 0,070 & & 0,002 & & & 0,076 & 0,951 & & 0,121 \\
\hline LoHueco Morph B*** & & & & & & & & & 7 & 0,001 & 4 & 0,009 & 0,189 & 5 & 5 & 0,009 & 2 \\
\hline Massecaps & & & & & & & & & & $\begin{array}{r}0,005 \\
9\end{array}$ & $\begin{array}{r}0,011 \\
7\end{array}$ & 0,109 & 0,749 & $\begin{array}{r}0,461 \\
8\end{array}$ & 0,093 & $\begin{array}{r}0,019 \\
8\end{array}$ & 0,503 \\
\hline & & & & & & & & & & & 0,023 & 0,010 & 0,002 & 0,004 & 0,000 & & 0,006 \\
\hline Patagosaurus* & & & & & & & & & & & 3 & 5 & 1 & 7 & 2 & 0,001 & 1 \\
\hline & & & & & & & & & & & & 0,190 & 0,005 & 0,081 & 0,000 & & 0,012 \\
\hline Euhelopus** & & & & & & & & & & & & 2 & 1 & 8 & 2 & 0,002 & 8 \\
\hline & & & & & & & & & & & & & 0,143 & 0,563 & 0,001 & 0,008 & 0,170 \\
\hline Shiramine form ${ }^{* *}$ & & & & & & & & & & & & & 3 & 9 & 4 & 6 & 7 \\
\hline & & & & & & & & & & & & & & 0,329 & 0,188 & 0,007 & 0,652 \\
\hline Astrodon $^{* *}$ & & & & & & & & & & & & & & 7 & 5 & 7 & 7 \\
\hline Neuquen titanosaur ** & & & & & & & & & & & & & & & $\begin{array}{r}0,021 \\
9\end{array}$ & $\begin{array}{r}0,007 \\
?\end{array}$ & 0.47 \\
\hline
\end{tabular}




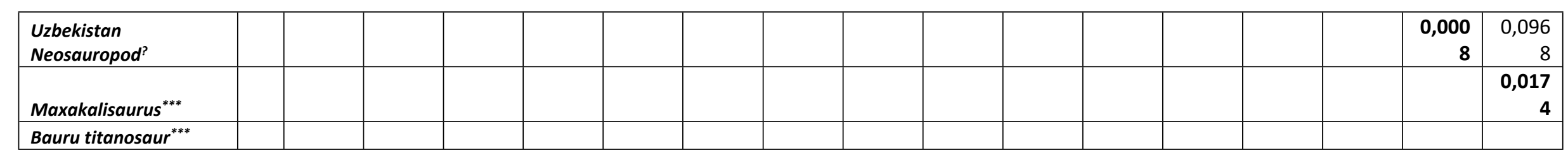
1 